\title{
Intrinsic Lattice Connections of Macaque Monkey Visual Cortical Area V4
}

\author{
Takashi Yoshioka, ${ }^{1,2}$ Jonathan B. Levitt, ${ }^{2}$ and Jennifer S. Lund ${ }^{1,2}$ \\ Departments of ${ }^{2}$ Psychiatry and ${ }^{2}$ Neurobiology, Anatomy, and Cell Science, University of Pittsburgh School of Medicine, \\ Pittsburgh, Pennsylvania 15261
}

We made focal iontophoretic as well as larger pressure injections ( $n=30 ; 19$ used for most analyses) of the tracer biocytin in visual area V4 of six macaque monkeys. The resulting transported label enabled mapping of intrinsic inter- and intralaminar connections within the region. We found that pyramidal neurons of layers 2 and 3 make extensive lateral projections within area V4, with oval or circular patches of terminals in layers 1-3. Any small patch of tissue (approximately $250 \mu \mathrm{m}$ wide) injected in the superficial layers appeared to connect reciprocally to patches scattered up to $3 \mathrm{~mm}$ around the injection. The patches of terminal label measure 250-450 $\mu \mathrm{m}$ across, spaced roughly $600 \mu \mathrm{m}$ (range, 450-1300 $\mu \mathrm{m}$ ) center to center, and where most densely packed they occupy $33 \%$ of the cortical area with approximately 3-4 patches $/ \mathrm{mm}^{2}$. Small injections in layers 4 and 6 did not produce contributions to these patchlike lattice connections, while injections in layer 5 gave very weak rising contributions to the superficial layer patch system. Large pressure injections of biocytin gave wider spread and more densely labeled patches, but their size and spacing appeared much the same as with small injections. The V4 pattern of label was compared to the patterns seen in areas $V 1$ and V2 after similar-sized injections of biocytin; patches in V1 and V2 were slightly smaller (roughly 250-300 $\mu \mathrm{m}$ across) and more closely spaced (425-450 $\mu \mathrm{m}$ center to center), consistent with earlier measures in these areas using HRP. The peak areal occupancy of patches was approximately the same, $27-33 \%$ in each region. We interpret these findings as indicating a functional repeat distance of 450-600 $\mu \mathrm{m}$ in area V4 (fixed tissue measures) with a patchy, discontinuous layout. Given the dimensions of the V4 intrinsic connectional system demonstrated here, it seems unlikely that it relates directly to the topography of specific afferent terminations or efferent neuron groups, which appear from other studies to have a larger scale of repeat (2-3 $\mathrm{mm}$ ). However, patches in V4 tend to aggregate, forming clusters extended in the mediolateral direction, suggesting a possible relation to coarser connection zones.

Received Nov. 19, 1991; reviewed Feb. 14, 1992; accepted Feb. 18, 1992.

We thank Suzanne Holbach and Tom Harper for excellent technical assistance, Marianne Davis for manuscript preparation, Susan Hockfield for making the Cat301 antibody available to us, and Edward Lachica, Vivien Casagrande, and David Fitzpatrick for advice on the biocytin technique. This work was supported by National Eye Institute Grants EY05282 (J.S.L.) and EY08098 (Eye and Ear Institute of Pittsburgh), an ARVO/ALCON postdoctoral rescarch fcllowship (T.Y.), and postdoctoral NRSA Award EY06275 (J.B.L.)

Correspondence should be addressed to Dr. Jennifer Lund, Institute of Ophthalmology, University of London, 11-43 Bath Street, London EC1 V 9EL United Kingdom.

Copyright (c) 1992 Society for Neuroscience $0270-6474 / 92 / 122785-18 \$ 05.00 / 0$
Long-range horizontal axons with regularly arranged clustered terminal fields can be a striking feature of intrinsic cortical organization. Numerous anatomical studies have shown these clustered intrinsic connections to be a ubiquitous feature of mammalian visual cortex. Patchy local connections have been demonstrated in the visual cortices of the tree shrew (Rockland et al., 1982), monkey (Rockland and Lund, 1983; Livingstone and Hubel, 1984a), cat (Gilbert and Wiesel, 1983), ferret (Rockland, 1985b), rat (Burkhalter, 1989), and even humans (Burkhalter and Bernardo, 1989). The functional role of these connections remains unclear, however.

In visual cortex, it has been suggested that the clustered horizontal connections relate to the columnar organization of orientation preference, such that groups of cells having similar orientation preferences are interconnected. This has been demonstrated most convincingly in cat V1 (Ts'o et al., 1986; Gilbert and Wiesel, 1989), although there may be a similar pattern in tree shrew (Rockland et al., 1982) and monkey (Ts'o and Gilbert, 1988). However, in cat area 18 , the rule may be for groups of cells having orthogonal orientation preferences to be connected (Matsubara et al., 1987; Kisvarday and Eysel, 1990; Crook et al., 1991). In primate V1, another organizational feature that may serve as a basis for intracortical connectivity is marked by the patchy distribution of cytochrome oxidase $(\mathrm{CO})$-rich tissue. Cells in CO-defined regions have distinct afferents and efferents, as well as distinct physiological properties (i.e., color selectivity and absence of orientation specificity), and a strong lattice of connections runs between them (Livingstone and Hubel, 1984a, b; Ts'o and Gilbert, 1988; Burkhalter and Bernardo, 1989).

Area V4 in the macaque monkey has been one of the most intensively studied extrastriate visual areas since Zeki (1973) originally reported that the cells in V4 were specialized for color. Although the precise role of $\mathrm{V} 4$ in processing chromatic information remains disputed (Zeki, 1980; Schein et al., 1982; Schein and Desimone, 1990), it is clear that V4 neurons also convey information about the spatial details of visual stimuli (Desimone et al., 1985; Desimone and Schein, 1987) and provide the major input to visual areas of the inferior temporal lobe (Desimone et al., 1980; Fenstemaker et al., 1984), thus making it an essential station in the pathway for object recognition (Ungerleider and Mishkin, 1982).

We were curious to examine the pattern of intrinsic connectivity in V4 for several reasons. Given that area V1 in all species examined displays periodic lattice connections, and area V2 in cats and monkeys also shows such arrays (Rockland, 1985a; Matsubara et al., 1987), we wanted to know if more distant extrastriate visual areas also show this pattern of connectivity. V4 seems particularly interesting in this regard, as there have 

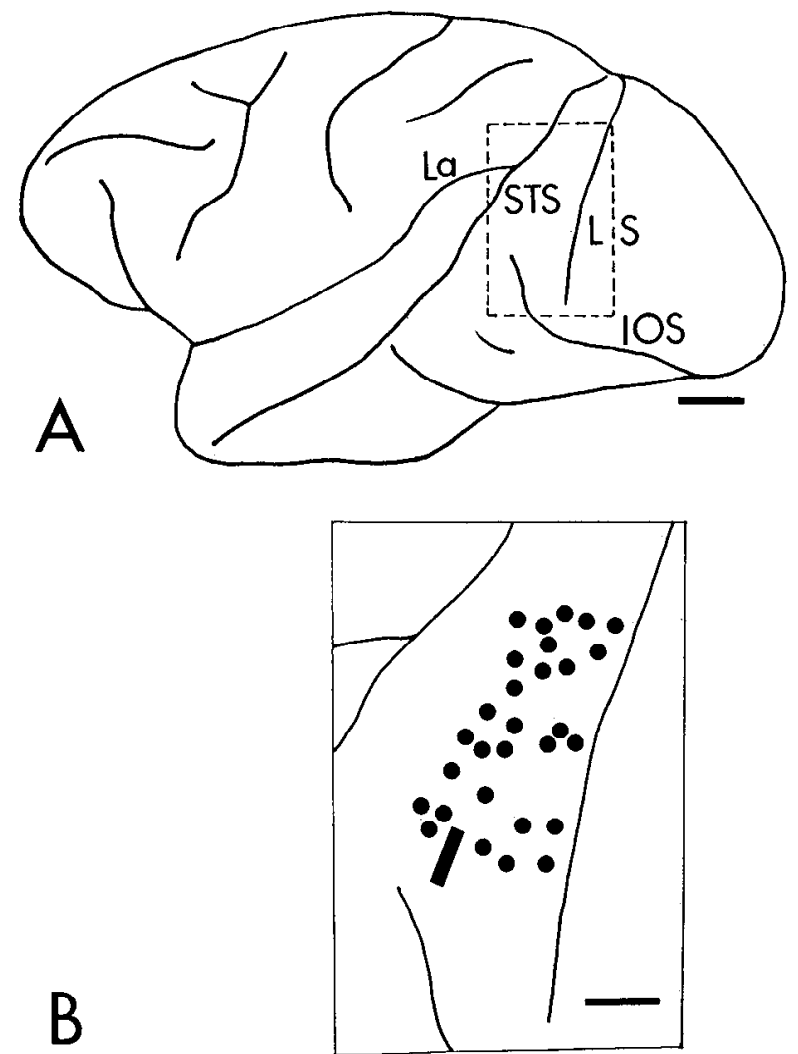

Figure 1. Location of injection sites in the macaque area V4. $A$, The prelunate gyrus region of area V4 is bounded by lunate sulcus $(L S)$, superior temporal sulcus $(S T S)$, lateral sulcus $(L a)$, and inferior occipital sulcus (IOS). $B$, Approximate locations of injection sites are indicated for small iontophoretic injections (solid circles) and a large pressure injection (solid bar) in the enlarged area defined by the broken line in $A$. Scale bars: $A, 5 \mathrm{~mm} ; B, 2 \mathrm{~mm}$.

been no clear demonstrations of columnar organization in this area. However, there are hints that V4 may have a modular organization that might provide a framework for intrinsic lattice connections - both from physiological studies on the disposition within V4 of cells having similar color selectivities (Tootell et al., 1980; Tanaka et al., 1986) as well as from anatomical studies on the topography of V4's afferents and efferents (Zeki, 1971; Zeki and Shipp, 1989; Van Essen et al., 1990). Additionally, a particular feature of V4 neuron responses seems to be the prominence of large suppressive surrounds (Desimone et al., 1985; Schein and Desimone, 1990), and we wished to examine local intraareal connectivity in V4 as a possible substrate for such center-surround interactions.

In the present study we have investigated the organization of intrinsic inter- and intralaminar connections in area $\mathrm{V} 4$ by making small iontophoretic as well as large pressure injections of biocytin, a new and very sensitive tracer that is readily taken up by neurons and rapidly transported principally anterogradely but also in the retrograde direction in adult primate cortex (Horikawa and Armstrong, 1988; King et al., 1989; Lachica et al., 1991).

A preliminary report of these results has appeared (Levitt et al., 1991).

\section{Materials and Methods}

Five female cynomolgus (Macaca fascicularis) monkeys $(3-4 \mathrm{~kg})$ and one male rhesus (Macaca mulatta) monkey $(10 \mathrm{~kg})$ were used to study the intracortical connections of area V4. Some of these animals participated in other tracing experiments unrelated to the current study. Animals were initially premedicated with atropine $(0.05 \mathrm{mg} / \mathrm{kg}, \mathrm{i} . \mathrm{m}$.) and tranquilized in their home cage with intramuscular injections of ketamine $(15 \mathrm{mg} / \mathrm{kg})$, and a catheter was inserted in either the saphenous or radial vein. The animal was then anesthetized with an intravenous infusion of pentobarbital (Nembutal, $1-2 \mathrm{mg} / \mathrm{kg} / \mathrm{hr}$ ) in lactated Ringer's solution $(5 \mathrm{cc} / \mathrm{hr})$ and placed in a stereotaxic apparatus. Local anesthetic ( $2 \%$ Lidocaine) was also administered topically at wound margins. The animal's temperature, respiration, and EKG were continuously monitored, and additional anesthetic was given as needed. All surgical procedures were performed under aseptic conditions, and treatment of animals was in accord with NIH guidelines.

We performed a craniotomy in the vicinity of stereotaxic coordinates P5, L25 and then visualized the location of the lunate sulcus and prelunate gyrus. Our placement of injections was guided by the pattern of sulci. Given that the precise boundaries of V4 remain ill defined, we aimed for the region of cortex on the prelunate gyrus medial to the anterior tip of the inferior occipital sulcus and lateral to the intersection of the superior temporal sulcus with the lateral sulcus. We also tried to restrict our injections to the crown of the prelunate gyrus or anterior bank of the lunate sulcus, and avoided making injections too far medially, laterally, or anteriorly. Prior studies include this region as part of their defined area V4 (Van Essen and Zeki, 1978; Maguire and Baizer, 1984; Gattass et al., 1988). Figure 1 illustrates the region of cortex in which we made injections; locations of our 30 injection sites are marked relative to local sulci.

Biocytin injections. After making a small slit in the dura at the chosen location, we placed a glass micropipette $(5-15 \mu \mathrm{m}$ tip diameter), containing $4 \%$ biocytin (Sigma) dissolved in $0.9 \%$ saline, in a micropositioner (David Kopf Instruments). We advanced the pipette to an appropriate depth and passed $6 \mu \mathrm{A}$ of anodal pulsed current $(7 \mathrm{sec}$ on, 7 $\mathrm{sec}$ off) through the tip for $10-15 \mathrm{~min}$ to inject biocytin. This enabled us to achieve focal microinjections having diameters of roughly 200 $300 \mu \mathrm{m}$ at varying depths throughout the cortex. We repeated the entire procedure a number of times at different locations in each hemisphere. In a few cases, to make larger injections, we also made pressure injections by gluing a glass micropipette (tip size, $50-100 \mu \mathrm{m}$ ) to the end of a Hamilton syringe and manually ejecting $0.2-1 \mu$ l. We separated adjacent injections by several millimeters to try to avoid overlapping label from different injections.

Histology. Upon the completion of injections, the animals were given antibiotic (Ditrim, $0.11 \mathrm{cc} / \mathrm{kg}$ ) and analgesic (Stadol, $0.05 \mathrm{cc} / \mathrm{kg}$ ) and were either maintained under anesthetic or recovered and allowed to survive for 2-24 hr. Animals were closely monitored during this time. They were then deeply anesthetized with Nembutal $(50-75 \mathrm{mg} / \mathrm{kg}$, i.p.) and perfused transcardially. We first rinsed with $1-2$ liters of warm $0.9 \%$ saline containing $0.5 \%$ sodium nitrite, followed by $3-4$ liters of $4 \%$ paraformaldehyde in $0.1 \mathrm{~m}$ potassium phosphate buffer (KPB; $\mathrm{pH} 7.4$ ) for $30 \mathrm{~min}$, and finally ran $1-2$ liters of $10 \%$ sucrose in $0.1 \mathrm{M} \mathrm{KPB}$ for $10 \mathrm{~min}$. Brains were immediately removed from the skull, blocked, and placed in $30 \%$ sucrose in $0.1 \mathrm{M} \mathrm{KPB}$ in the cold $\left(5^{\circ} \mathrm{C}\right)$ until they sank They were then sectioned either coronally or tangential to the pial surface at $40-50 \mu \mathrm{m}$ on a freezing microtome. Sections were maintained in absolute serial order and typically allotted to four series given different treatments; the first and third series were reacted for biocytin (one of which was cobalt intensified), the second series was reacted for cytochrome oxidase, and the fourth series was stained for Nissl or Cat-301 immunopositivity (Hockfield et al., 1983; DeYoe et al., 1990) to aid in identification of areal boundaries. Area V4 can be distinguished from adjacent cortical areas by its low density of Cat-301-labeled cells, although its precise borders remain indistinct with this method since the Cat-301 level drops off gradually.

For biocytin histology, we used a modified protocol of Horikawa and Armstrong (1988) and King et al. (1989). Briefly, sections were incubated overnight in the cold in a solution of $0.7 \%$ Triton, $2 \%$ normal rabbit serum (NRS), and $0.02 \mathrm{M} \mathrm{KPB}$. After rinsing the tissue in $0.02 \mathrm{M} \mathrm{KPB}$, followed by a final rinse in $0.02 \mathrm{M} \mathrm{KPB}$ containing $2 \% \mathrm{NRS}$, the sections were incubated in Elite-ABC solution (Vector Laboratories; 1:130 dilution with $0.02 \mathrm{M} \mathrm{KPB}$ ) for $1-2 \mathrm{hr}$. Some sections were soaked for 5$10 \mathrm{~min}$ in a $1 \%$ cobalt chloride solution in $0.02 \mathrm{M}$ Tris buffer to intensify labeling (Adams, 1977). Finally, label was visualized with peroxidase histochemistry using diaminobenzidine. For Cat-301 staining, we followed the protocol described by DeYoe et al. (1990).

Analysis. Sections were examined by light microscope under both bright-and dark-field illumination. Dark-field microscopy showed clear 


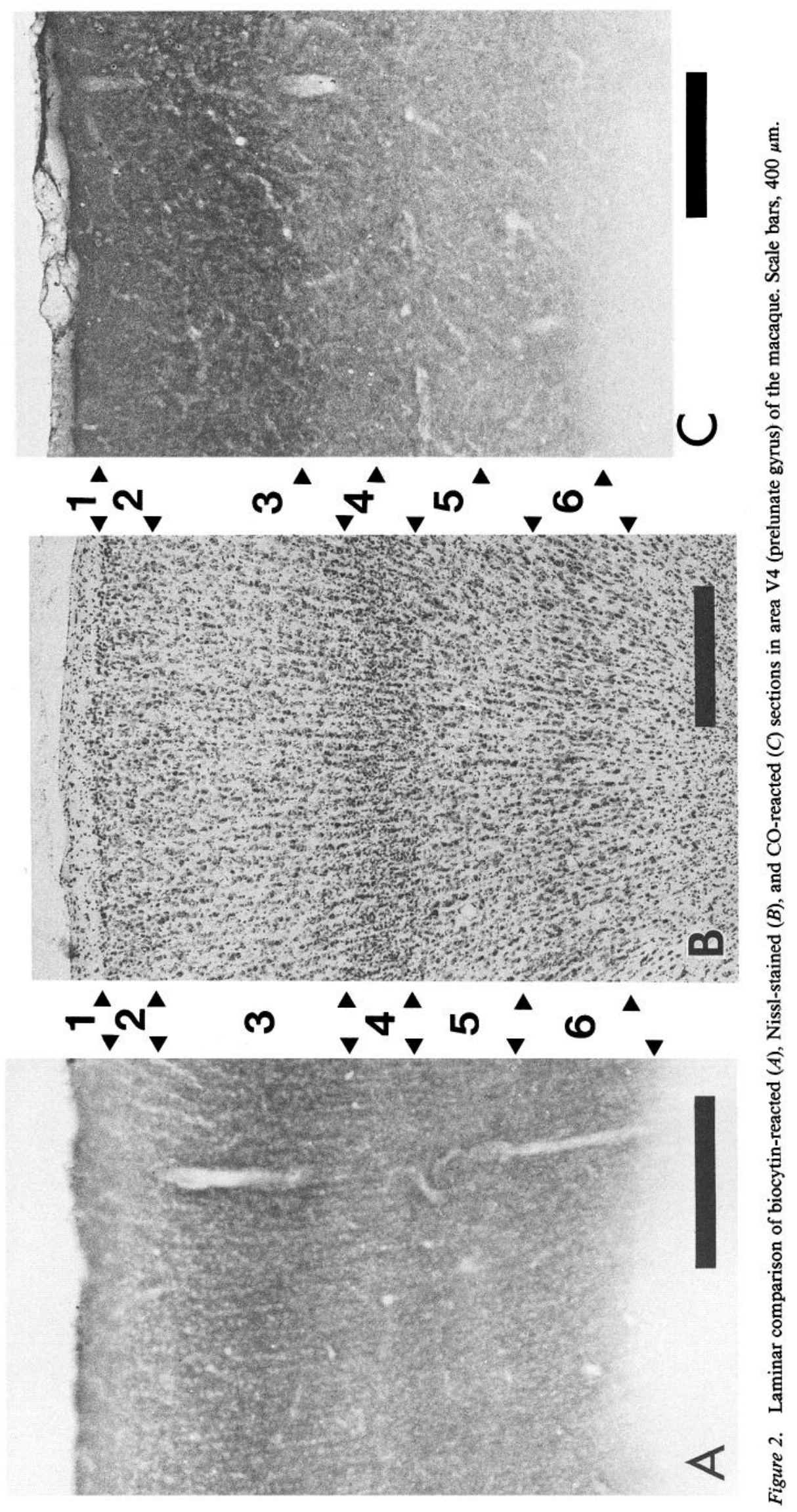




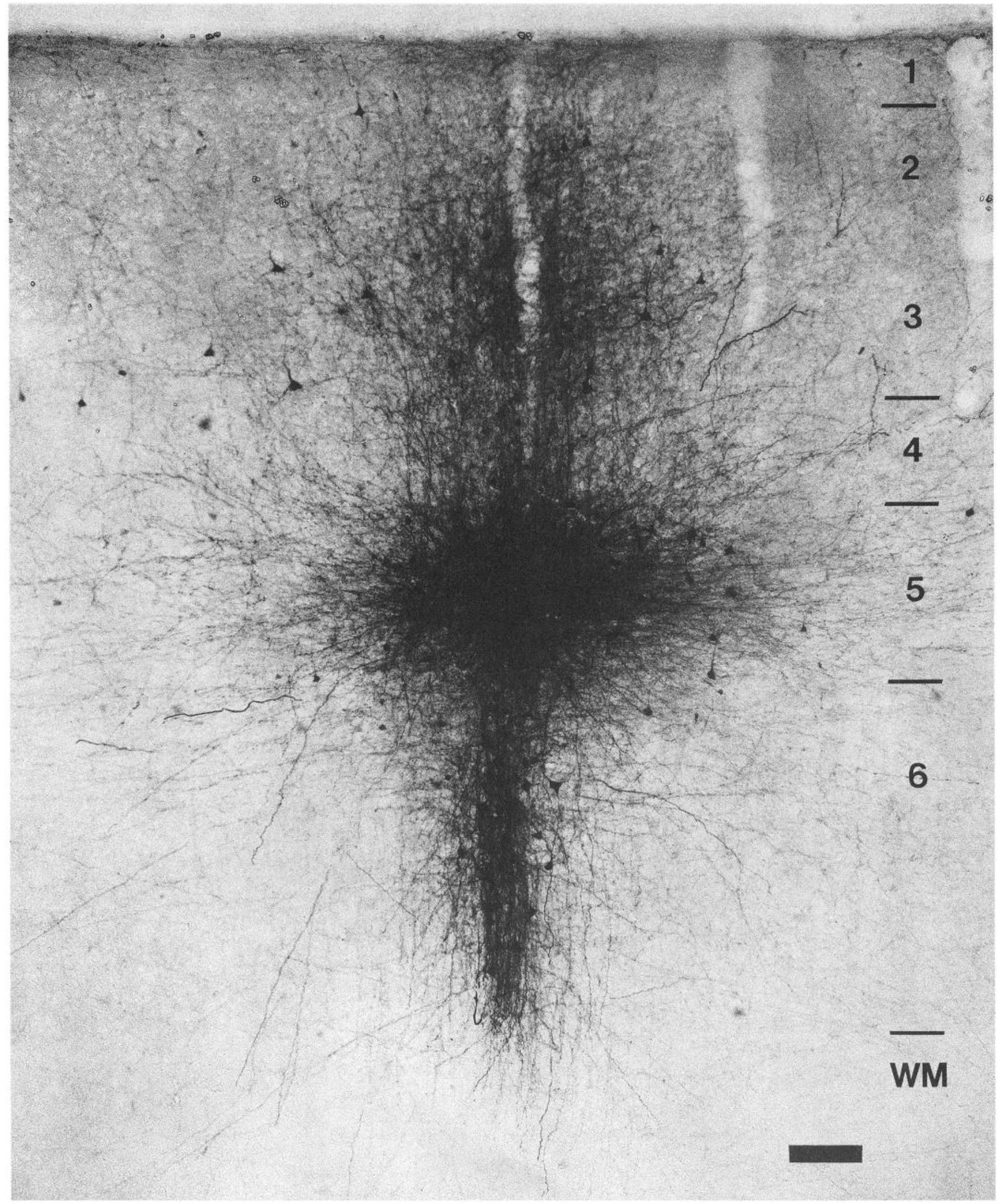

Figure 3. Photomicrograph showing a biocytin injection into layer 5 . The focus of the iontophoretic injection in layer 5 measures approximately $200 \mu \mathrm{m}$ in diameter. Horizontally spreading fibers are seen predominantly in layers 5 and 3 . Large labeled pyramidal neurons are present in layers 3 and 5 as well as 2 and 6 . Scale bar, $100 \mu \mathrm{m}$. 
labeled fibers and terminals when sections were not cobalt intensified, and proved especially useful in identifying even lightly labeled terminals and fibers. Since many of the coronal sections were not cut along the true vertical axis between pia and white matter, serial reconstructions were necessary to examine the interlaminar connections local to the injection as well as the pattern of horizontal spread of fibers and terminals within single layers. We obtained plots of labeled neurons and fibers by tracing the injections using a microscope drawing tube. Composite diagrams were constructed by superimposing drawings of adjacent sections, using blood vessels and other landmarks to align sections.

\section{Results}

While 30 injections were made, 19 well-labeled injection sites served for this analysis for reasons relating to quality of reaction and tissue integrity.

\section{Laminar numbering system}

The laminar identification and numbering system of area V4 is based on the examination of the tissue sections reacted for biocylin, Nissl, and $\mathrm{CO}$ as illustrated in Figure $2 A-C$, respectively. The Nissl-stained section showed two bands of cell-dense layers identified as layers 4 and 6 (Fig. $2 B$ ). For the sections reacted for biocytin (Fig. $2 A$ ), layer 4 appears to be rather pale sandwiched between dark bands in layer 3 and the upper half of layer 5 ; in addition, layer 6 was also darkly labeled. These three dark bands in biocytin sections were best visualized when cobalt intensification was used prior to the peroxidase reaction in the histological procedure. These sections could be used to distinguish cortical layers. The presence of a dark upper band and lighter lower band in layer 5 might support subdividing this layer into $5 \mathrm{~A}$ and $5 \mathrm{~B}$. However, we feel that the organization of afferents and efferents in layer 5 and its internal organization need to be examined in more detail before we subdivide it. Sections reacted for $\mathrm{CO}$, as illustrated in Figure $2 C$, showed a very dark upper band (from layer 1 to layer 3 ) and a relatively dark band in upper layer 5 . This pattern differs from $\mathrm{CO}$ labeling in V1 or V2, but it cannot be used as a reliable areal boundary marker. Layer 3 within the dark upper band contains heavily labeled pyramidal cells that are also visible in upper layer 5 of sections reacted for a sufficiently long period of time.

\section{Laminar organization of $V 4$}

Injection sites generally appeared as a uniformly dark circular deposit of biocytin about $200-300 \mu \mathrm{m}$ in diameter; this was accompanied by an extremely dense surround of labeled fibers (see Fig. 3). Both anterogradely and retrogradely labeled neurons were observed after biocytin injections, confirming a recent report (Lachica et al., 1991) that this substance is transported bidirectionally. In some cases the biocytin appeared to have been taken up by neurons damaged by the entering injection pipette. While these damaged neurons showed filling of somata (and sometimes of the initial segment of the apical dendritc), they did not appear to contribute to the extensive projections that arose from the iontophoretic injection site itself. Figure 3 shows a typical biocytin injection, here made into layer 5 , with labeled fibers forming a narrow column throughout layers 1-6. This column follows what we will call the "radial axis"; this term is used for the line drawn between pia and white matter running through the heart of the injection and passing along the local columnar axis traveled by most axon trunks and apical dendrites of pyramidal neurons (see Fitzpatrick et al., 1985).

In order to see a clear picture of the laminar projections around the biocytin injections, serial reconstruction of coronal sections was made. Figure 4 summarizes the results of five representative injections placed at different cortical depths after such serial reconstructions. This laminar analysis is based on a total of 15 focal injections. Single sections for these injections are also shown in photomicrographs in Figures 5-7. The patterns of cell and fiber filling differed for each of these injections and suggest different patterns of projections for cells at different depths through the cortex.

\section{Injection in layers 1 and 2}

Figure $4 A$ summarizes the pattern of biocytin label after an injection involving layers 1 and 2. (This injection site is also shown in Fig. $5 \mathrm{~A}$.) We found retrogradely labeled cells scattered lateral to the injection site chiefly in layer 2 but also occasionally in layer 3. These labeled cells almost invariably lay in patches of labeled fibers that occurred at intervals around the injection site. This suggests that the injection site received projections from cells in patches of cortical tissue to which it projected in reciprocal fashion. Presumably a fcw cclls in these patches projected heavily enough to the injection site to take up enough biocytin to become visibly labeled in retrograde fashion. In general these cells did not show a clearly visible axon arbor of their own, so it is presumed that most fiber labeling observed was anterograde filling arising from neurons in the injection site or well filled in layer 3 immediately under the injection via their apical dendrites (see Fig. $5 A$ ). Fibers spread tangentially in all directions from the injection site, predominantly in layers 1 and 2. Fewer fibers spread laterally in layer 3, particularly near the junction of layers 3 and 4 . These layer 3 fibers could in some cases be observed to emit rising collaterals, and these collaterals produced a cluster of small branches and terminals in layers 3 and 2 contributing to terminal patches already served by layer 1 and 2 fibers. The terminal patches around the injection site could be robust - measuring up to $450 \mu \mathrm{m}$ across - or very slight with just a few disorganized terminal fibers. The more distant patches (2-3 $\mathrm{mm}$ from the injection site) were least robust. The distance from the injection site to the nearest patch varied from $500 \mu \mathrm{m}$ to $1.1 \mathrm{~mm}$. Distance between terminal patches as seen in the pia to white matter sections averaged $850 \mu \mathrm{m}$. The patches appeared to be present all around the injection site for a distance of at least $3 \mathrm{~mm}$ and did not appear to be aligned in any specific fashion (e.g., in rows or stripes). Fascicles of labeled fibers descended vertically from the injection site and entered the white matter. In layer 5, horizontal collaterals emerged from the descending trunks and spread widely within layer 5 as long, straight trunks. Under terminal patches in layers 2 and 3 close to the injection site, a slight scatter of fine fibers appeared in layer 5 and rising axon branches passed to layers 3 and 2 to contribute to many of the superficial clusters of terminals. No evidence was seen of terminal contributions to layers 4 or 6 , and very few horizontally running fibers appeared in these layers.

\section{Injection in layer 3}

Figure $4 B$ summarizes the pattern of label around an injection site placed in layer 3. (A section from this injection is also shown in Fig. 7.) A column of filled neurons was found through the cortical depth including cells in layers $2,3,4,5$, and upper 6 . Within the column, large upper layer 5 cells were particularly well filled, perhaps via their apical dendrites, and showed both apical and basal dendritic filling; the column was narrowest in layer 6 (with rather few cells labeled). Scattered labeled cells occurred in layers 2 and 3 in a zone $600-800 \mu \mathrm{m}$ around the 

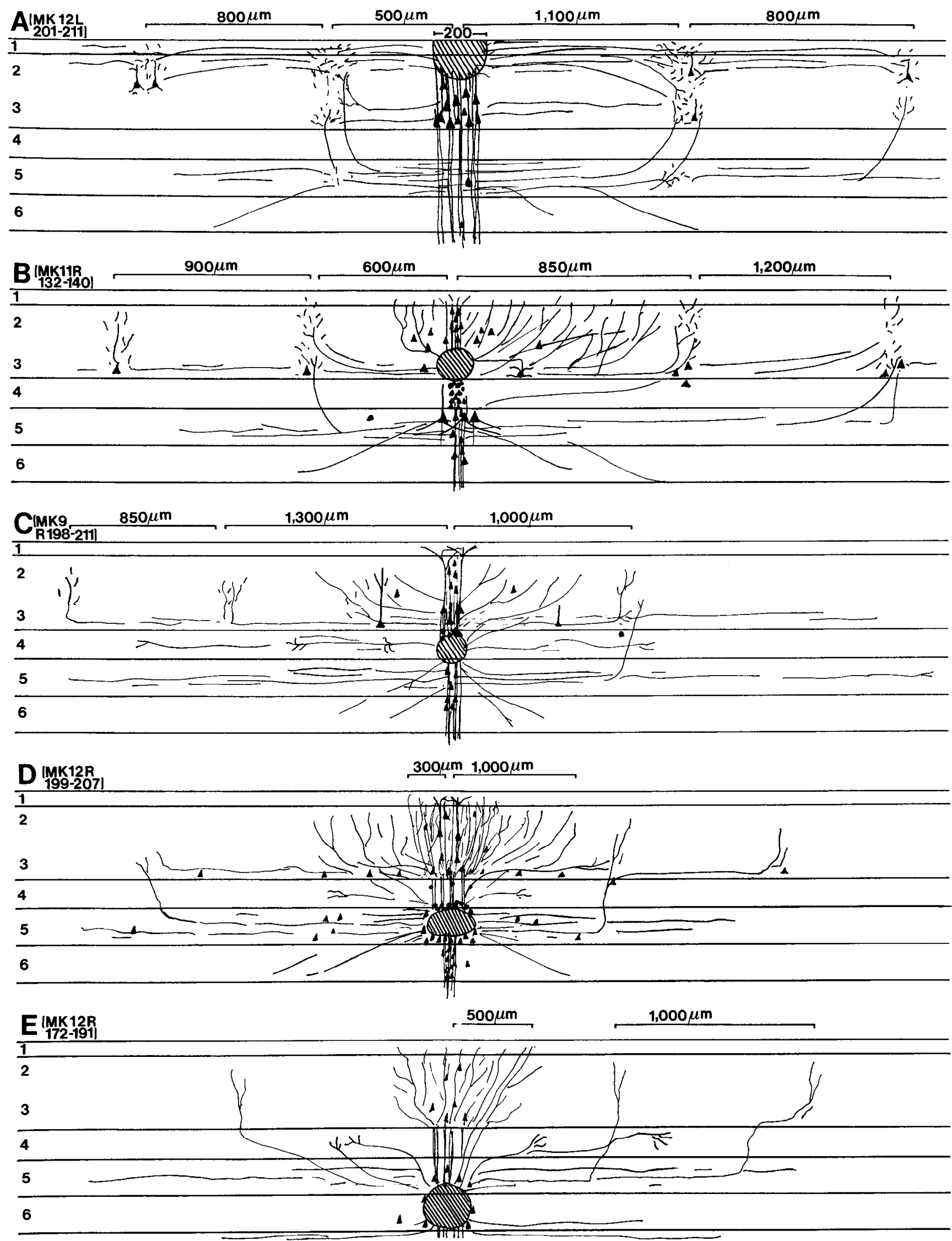

Figure 4. Diagrams summarizing patterns of anterograde and retrograde label seen after small ( $200 \mu \mathrm{m})$ biocytin injections made at different depths in V4. The patterns were reconstructed from series of coronal sections. $A$, Injection into layers 1 and 2 (see also Fig. $5 A$ ). $B$, Injection into layer 3 (see also Fig. 7). $C$, Injection into layer 4 (see also Fig. $5 B$ ). $D$, Injection into layer 5 (see also Fig. 3). $E$, Injection into layer 6 (see also Fig. $5 C$ ). See Results for further description. Note that the diagrams are not drawn to scale. 
injection site and more distantly in deep layer 3, or the border of layers 3 and 4. Pyramids were labeled in conjunction with clusters of terminal label in layers 2 and 3 . Coarse fibers spread laterally in layer 3 , turning upward at intervals to contribute to the laterally placed clusters of terminals spaced $700 \mu \mathrm{m}$ to 1.2 mm apart (see Fig. 7). Closer to the injection site, a cloud of coarse rising and spreading fibers was found associated with the injection site, spreading out and terminating over almost 900 $\mu \mathrm{m}$ to one side of the injection, while on the other side of the injection a gap in fiber labeling occurred before the first terminal cluster placed about $600 \mu \mathrm{m}$ from the injection locus. This eccentric spread of local fibers was not uncommon around injection sites; it did not seem to be due to entry damage by the injection pipette and seemed to emanate from the layer 3 pyramidal neurons, creating partial terminal "filling in" locally between injection and nearest patches. Fascicles of fibers ran vertically down from the injection site to the white matter, and axon collaterals spread laterally in layer 5 . Occasional fibers turned upward from layer 5 to enter the patches of terminals in layers 2 and 3 . The patterns of cell label observed under this layer 3 injection suggest that layer 3 is a target of focused projections from small pyramidal neurons in layer 4 and upper layer 6 , as well as a source for wide-spread lateral connections. Pyramidal neurons in patches in deeper layer 3 around the injection site appeared to contribute terminal collaterals principally to the layer 3 region itself, since they were retrogradely labeled after this injection but were not prominent following the layer 1-2 injection. Another example of a layer 3 injection site is shown in Figure 6 with a strong projection to a lateral patch (arrows). Fibers continue in layers 2 and 3 to more distant patches (not shown).

\section{Injection in layer 4}

The injection in layer 4 (Figs. $4 C, 5 B$ ) gave a column of labeled cells in layers 2, 3, 5, and upper 6. Label in layer 4 was not aligned with laterally placed superficial patches of labeled terminals and occurred mainly within $1 \mathrm{~mm}$ of the radial axis; this layer 4 terminal label may be intrinsic layer 4 projections, but there is also the strong possibility that the fibers that appeared to terminate in layer 4 could be labeled incoming afferents that passed through the injection site. The presence of labeled cells in upper layer 6 may indicate a preferential projection of upper layer 6 to layer 3 , rather than to layer 4 , since these cells were also labeled following layer 3 injections. Pyramids in layers 2 and 3 immediately above the injection site were well labeled and may have contributed to the projection to lateral patches observed in layers 2 and 3 .

\section{Injection in layer 5}

Labeled cells formed a very narrow column throughout layer 6 (Figs. 3, 4D); both local and scattered distant labeled cells were present in layer 5 , and a few cells were labeled in lower layer 4 very close to the injection site. Cells were also found broadly scattered in layer 3, especially at the layer 3-4 border, over 1 $\mathrm{mm}$ to each side of the injection. A more focused group of cells, including cells with biocytin-filled apical dendrites, was labeled in layer 2 over the injection site. Fibers with some terminals were found in layer 4 spreading from the radial axis, and a light scatter of lateral projections rose from layer 5 into layer 3 , but no strong superficial layer terminal patches were observed. Neither were retrogradely labeled cell clusters seen in layer 5. A broad fan of coarse fibers spread outward from rising trunks, reaching the base of layer 3 over the injection site, giving a spread of about $1 \mathrm{~mm}$ of scattered fibers around the radial axis with a more focused dense core of fibcrs rcaching about $300 \mu \mathrm{m}$ from the radial axis (see Fig. 3).

\section{Injection in layer 6 (plus lowermost 5)}

Scattered cells were labeled laterally near the injection site in layer 6 , and a light scatter of cells was labeled in layers 5 and 2-3 over the injection site (Figs. $4 E, 5 C$ ). The only cells labeled in layer 4 lay on the pipette entry track and did not appear to give rise to projections. Spreading fibers, which may include afferent fibers, rose from the injection site to produce terminal labeling in layer 4 . Immediately above the injection site fibers arborized in layers $1-3$, reaching approximately $500 \mu \mathrm{m}$ from the radial axis. Occasional sparse fibers rose from layer 5 to give very light contribution, over $2-3 \mathrm{~mm}$ to layers 3 and 2 . No prominent terminal clusters were found in the superficial layers. Deep layer 6 and layer 5 contained coarse laterally running fibers.

\section{Tangential organization of patch system}

The patchy distribution of terminal label in the superficial layers that we saw in the coronal sections was seen more clearly in the tangential plane. This analysis is based on four injections. The coronal section shown in Figure 8 turned out to be nearly tangential to the pia because the injection site (in layer 3 ) was close to the anterior bank of the lunate sulcus. Most patches were located in layer 3 and included labeled cells as well as terminals. To visualize these patches better, we made a large pressure injection of biocytin $(1.0 \mu \mathrm{l})$ into $\mathrm{V} 4$ and sectioned the tissue tangentially. Figures 9-11 show the result of this injection. The striplike injection site extended from layer 1 through layer 4 . The patches visible in layers 1 and 2 are aggregations of terminals without cell bodies (but with occasional filled dendrites; see Fig. 9); howcver, a decper section shows that the patches in layer 3 contain labeled cells as well as terminals (Fig. 10), again suggesting that the patch system seen in upper layers is formed mostly by the axons of neurons whose somata are located in layer 3 (and to a lesser extent in lower layer 2). A high-power photomicrograph of the injection at the level of layers 1 and 2 (Fig. 9B) shows extensively labeled fibers projecting away from the injection site, whose terminals cluster at a relatively regular interval of 450-600 $\mu \mathrm{m}$ (center to center) near the injection site and $800-1300 \mu \mathrm{m}$ farther away from the injection. These biocytin-labeled patches of axon terminal fibers appear to be cylindrical in shape throughout layers 2 and 3, with somewhat larger arbor spread in layer 1 . In tangential section, the presence of terminal label in layer 5 is uncertain since the collaterals leaving the horizontal fibers in layer 5 , making their way to the superficial patches, can be confused in cross section with the terminal label. Certainly any terminal patch system in layer 5 is extremely weak compared to that in the superficial patches.

Although the size of these patches in tangential view varies from patch to patch, the typical patch seems to be round or oval with the size of $250-450 \mu \mathrm{m}$ across. These patches occur as far as $2.6-3.5 \mathrm{~mm}$ from the injection site. The overall spread of patches from the injection site may depend on the sensitivity of the tracers used, and the actual spread of lateral connections from single $250-\mu \mathrm{m}$-wide neuron clusters is likely to be farther than the value obtained in this study.

Because no single tangential section contained all patches observable in a section series, a serial reconstruction was made 


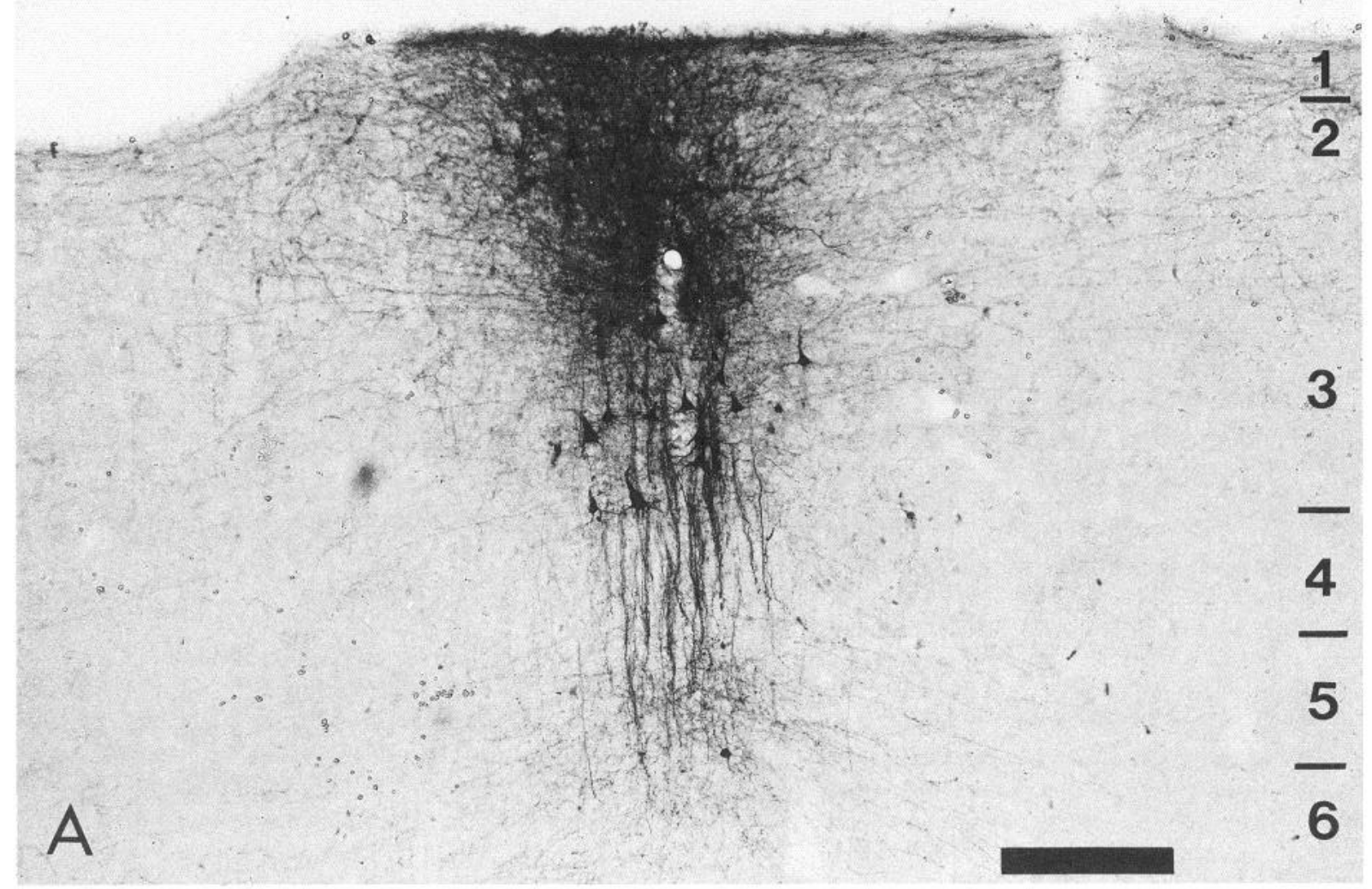

Figure 5. Photomicrographs showing biocytin injections into different layers in V4. A, Pyramidal cells are labeled in layer 3 under a biocytin injection into layers 1 and 2 (probably via their apical dendrites), but no cells are labeled in layer 4 , which shows as a pale band free of laterally spreading fibers between layers 3 and 5 . Laterally traveling biocytin-labeled fibers are prominent in layers $1-3$ and 5 . B, A biocytin injection into layer 4; a column of labeled cells is found from layer 2 through upper layer 6 . $C$, A biocytin injection into layers 6 and lowermost layer 5 . Labeled neurons are found in layers 2, 3,5, and 6. Extensive lateral spread of fibers is seen in layers 5 and 6 . See summary diagrams of label resulting from these injections in Figure 4. Scale bars, $200 \mu \mathrm{m}$.

from eight alternate $50 \mu \mathrm{m}$ tangential sections reacted for biocytin through layers $1-3$, and patches seen in at least two consecutive serial sections were traced (Fig. 11). When a square frame $(1 \times 1 \mathrm{~mm})$ was applied to an area where patches were most dense, the patch density was 3.8 patches $/ \mathrm{mm}^{2}$, with an area occupancy of $33 \%$.

In order to see if the size of injections made any difference in the patch size and interval, we also made small iontophoretic injections of biocytin (Fig. 12) whose injection core was smaller than single V4 patches surrounding a large pressure injection of biocytin seen in Figures 9-11. Serial reconstruction of tangential sections after such small iontophoretic injections indicates that the dimensions of patch size (250-400 $\mu \mathrm{m}$ diameter) and patch interval (450-1100 $\mu \mathrm{m})$ are roughly equivalent to those found by a large pressure injection (patch size, $250-450 \mu \mathrm{m}$ diameter; interval, 450-1300 $\mu \mathrm{m}$ ), although the total spread and number of patches are smaller.

\section{Discussion}

In this study we utilized iontophoretic focal microinjections as well as large pressure injections of biocytin to examine the pattern of intrinsic interlaminar and horizontal connectivity in area V4. It is our impression that biocytin is superior to HRP in its labeling of the intrinsic lattice systems, giving more labeled fibers from similarly sized injections than does HRP. We are uncertain, however, whether its retrograde labeling is any more sensitive. By using small (200-300 $\mu \mathrm{m})$ injections, we were able to restrict injections to single cortical layers, and thereby determine the distinct inter- and intralaminar projections of neurons located at different depths within the cortex. Although little is known about laminar differences in receptive field properties in V4, the patterns of interlaminar connectivity we observe suggest possible functional roles for this circuitry. The strongly focused vertical interlaminar projections presumably reflect the circuitry by which cells that are not recipients of direct V2 input (i.e., outside layer 4 and the base of layer 3B) acquire their visual field and retinotopic order across V4; the more divergent laterally spreading inter- and intralaminar projections, which are notably absent from layer 4 , presumably serve to integrate functionally distinct input zones, or enlarge the receptive fields of postsynaptic neurons. This type of intraareal circuitry has already been noted in V1 (Blasdel et al., 1985; Fitzpatrick et al., 1985). We summarize our conclusions concerning aspects of intrinsic pyramidal neuron connectivity in Figure 13.

We found that pyramidal neurons of layers 2 and 3 make robust, patchy connections in layers 1-3 around an injection zone, and these lateral connections spread up to $3 \mathrm{~mm}$ away from the injection site (total spread of $6 \mathrm{~mm}$ ). Terminal label in patches was concentrated in layers $1-3$. We presume that any small region of V4 cortex is similarly connected to patches scattered up to at least $3 \mathrm{~mm}$ distance around it, since all of our injections involving the superficial layers resulted in laterally 

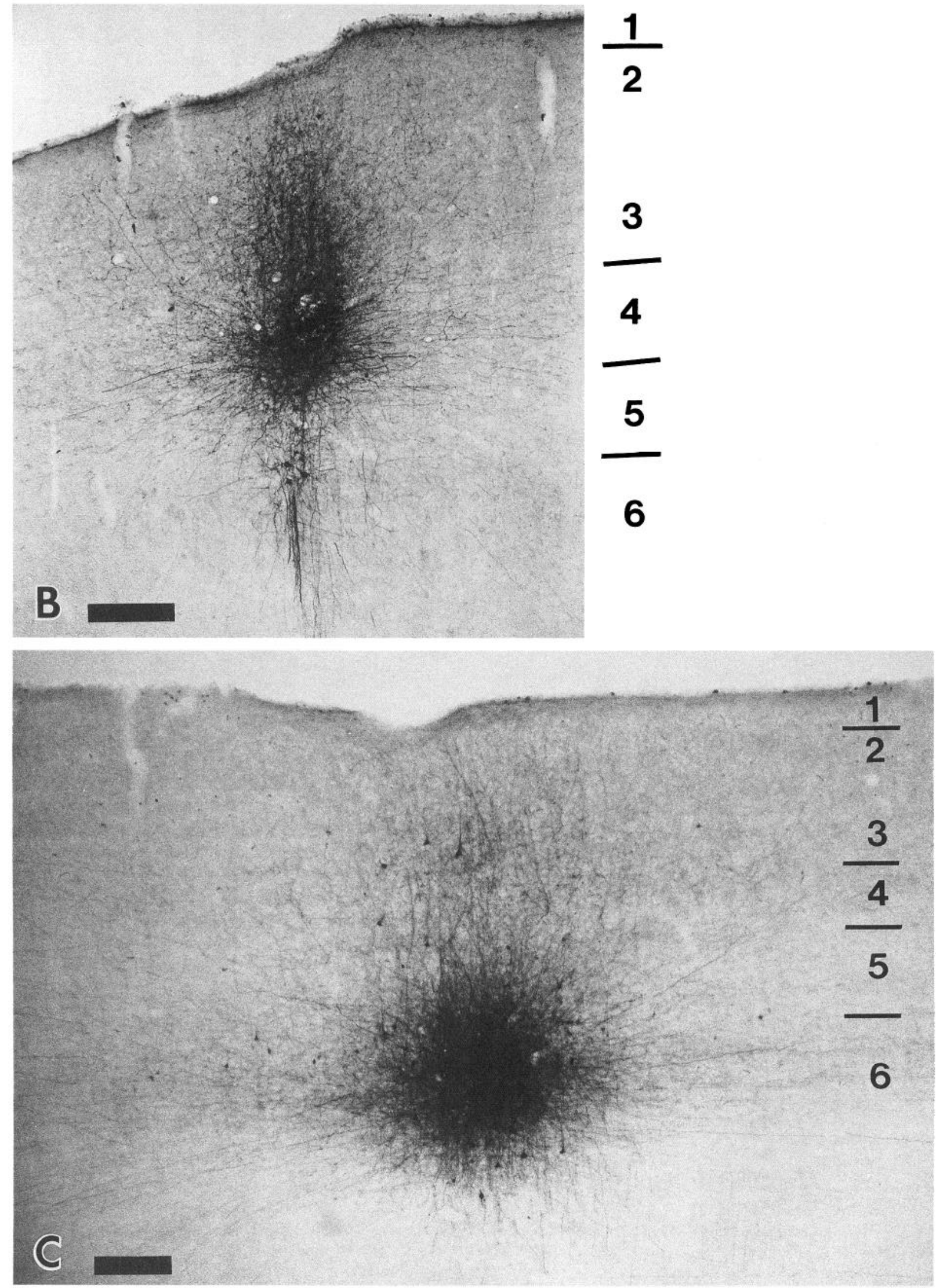


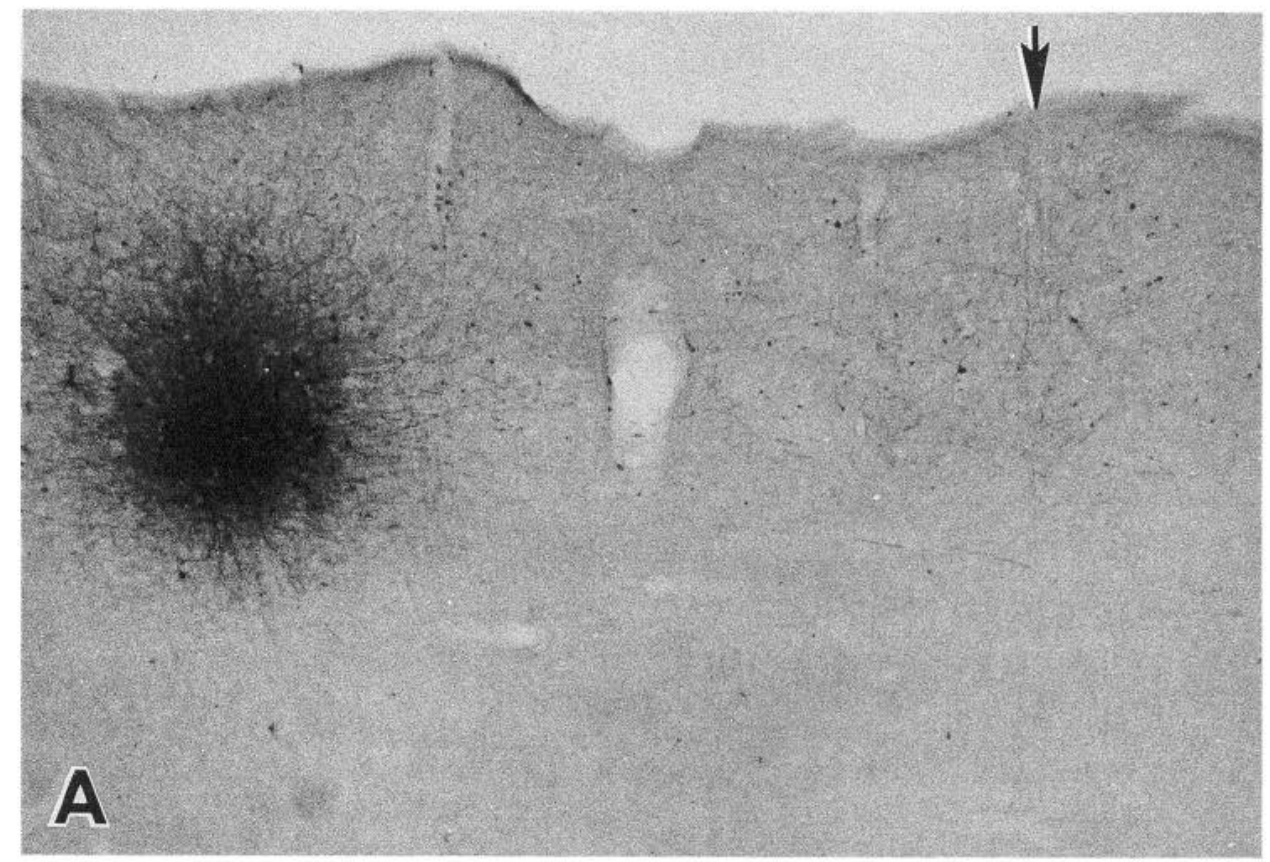

Figure 6. Bright-field $(A)$ and darkfield $(B)$ photomicrographs showing a biocytin injection into layers 2 and 3 . A cluster of cells and terminals (arrows) is found as a laterally placed patch extending throughout upper layers 1-3. Scale bars, $300 \mu \mathrm{m}$.

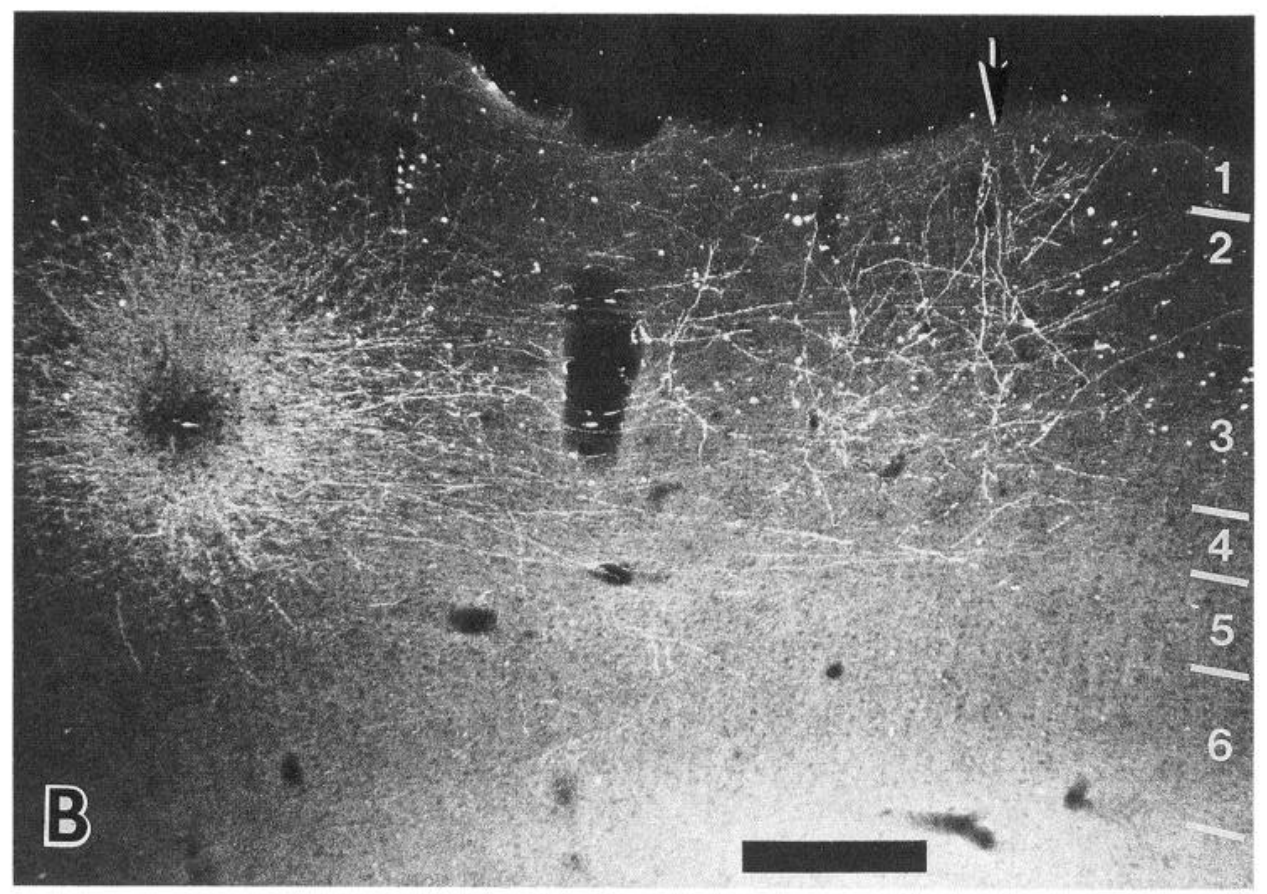

offset terminal patches. The emphasis of the patchy connectional system in the superficial layers, and its absence in layer 4 and deeper layers suggest that the lattice array may represent the evolution of new functional characteristics in area V4 that are not represented in the afferents to this area. A lesser contribution to the superficial layer patches is made by fibers rising from layer 5-probably originating from both layer 5 pyramids as well as from axon collaterals given off from the layer 5 lateral branches of descending axon trunks of layer 2-3 pyramids (see Fig. 13). Cells of layer 4 and layer 6 do not appear to provide any significant laterally spreading connections to the patches, but rather may engage primarily in local columnar connections or, in the case of layer 6 , diffuse spreading connections not engaging the lattice. Pyramidal cells of layers 3 and 5, in addition to contributing to the long lateral patchy projections, may also provide a more locally spreading set of connections in layers 2 and 3 that appear to fill in partially or wholly the layer 2-3 territory between the injection site and the nearest laterally connected patches.

The overall territory served by the patchy connections of a single $250-\mu \mathrm{m}$-wide region of V4 neuropil tends to be greater mediolaterally than anteroposteriorly - up to $6 \mathrm{~mm}$ or more along the major axis. Rockland (1985a) observed a similar phenomenon in squirrel monkey V2. This means that the greatest spread of connections from a point in V4 is orthogonal to lines of constant eccentricity in the retinotopic map (Gattass et al., 1988), and the spread of connectivity is compressed in the same way as the visual field map of this area. This suggests that, as 


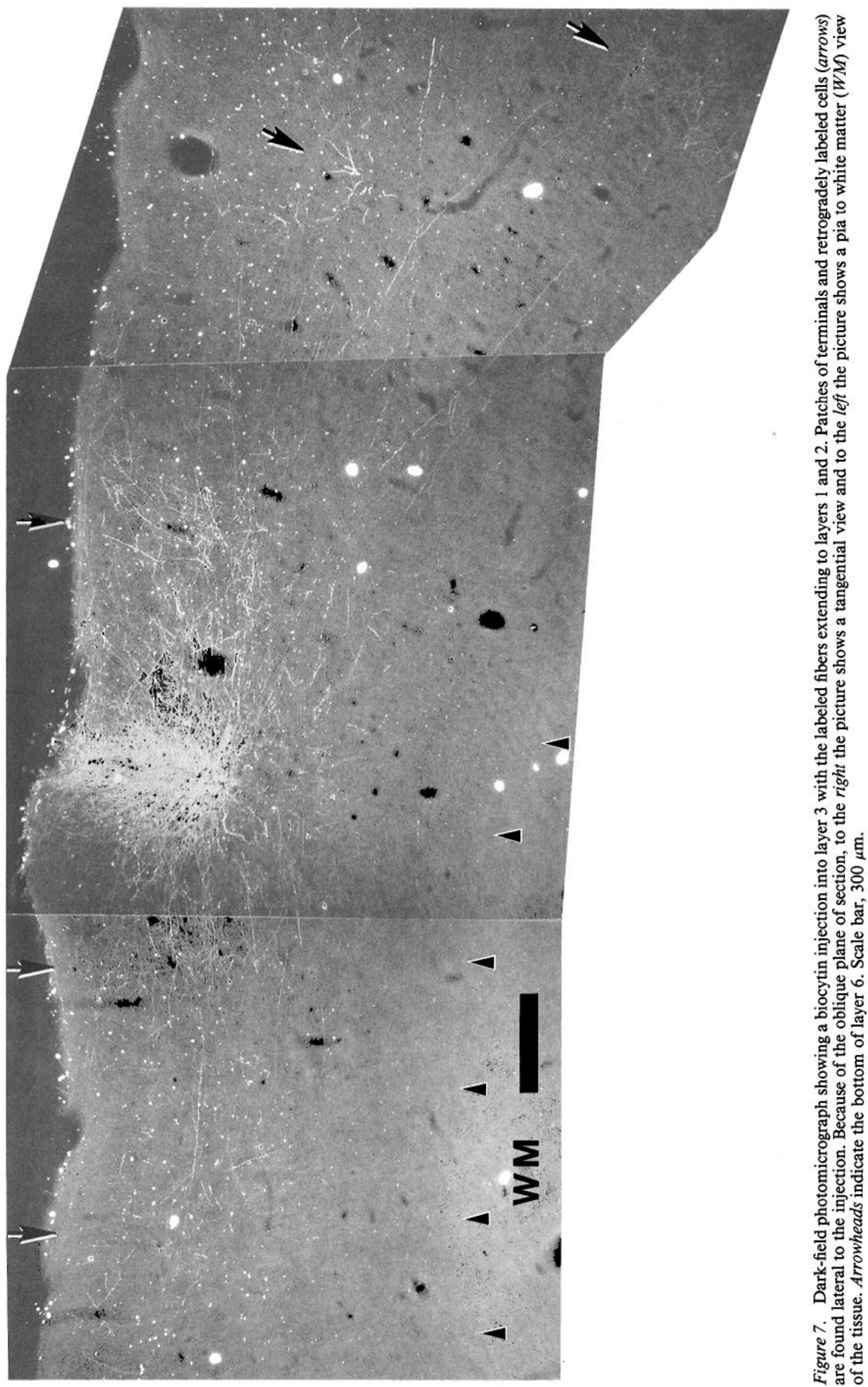




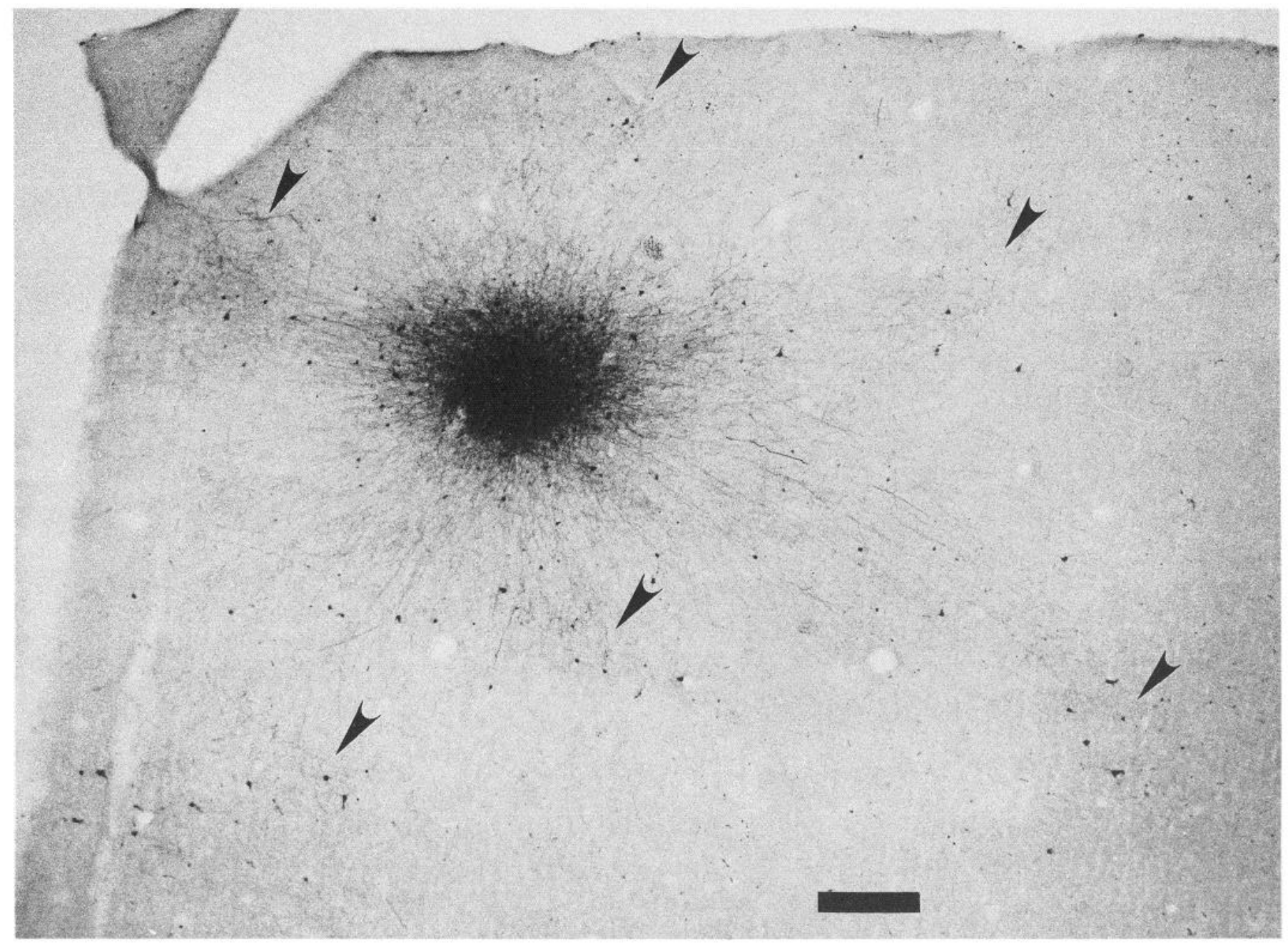

Figure 8. Bright-field photomicrograph showing a tangential view of a biocytin injection site into layers 2 and 3 . Patches of labeled terminals and neurons (arrowheads) in layer 3 are surrounding the injection site. Scale bar, $300 \mu \mathrm{m}$.

Matsubara et al. (1987) described for the spread of label in cat area 18 , the visual field map may to some extent govern the distribution of local connections. We saw consistent patterns of patches in all our focal injections. However, given the reports of V4 subdivisions in macaque monkeys (Maguire and Baizer, 1984) and in squirrel monkeys (Cusick and Kaas, 1988), it is possible that our connections are both within and between subdivisions of V4. This warrants further attention.

The presence of such a lattice of patchy intrinsic connections in area V4 raises the question of the functional role played by such lattices. Patchy intrinsic connections seem to be a fundamental feature of all visual areas, indeed perhaps of all cortical neuropil. In all mammalian species studied, from rat to human, the intrinsic connectivity of primary visual cortex is patchy (Rockland et al., 1982; Gilbert and Wiesel, 1983; Rockland and Lund, 1983; Livingstone and Hubel, 1984a; Rockland, 1985a; Burkhalter, 1989; Burkhalter and Bernardo, 1989). In cats and primates, a similar pattern of connectivity is seen in the second visual area (V2), and Matsubara and Phillips (1988) and Wallace et al. (1991) have observed intrinsic lattice connections surrounding focal injections in cat primary auditory cortex as well. We note that many of the features described here for V4 intraareal and interlaminar connectivity are also those described for cat auditory cortex. We also note that the punctate connected regions in intrinsic connectivity may form part of a larger pattern of connectivity that may differ between species. For instance, the patches merge to make stripes in tree shrew V1, whereas in macaque V1 they merge to form a more honeycomb pattern. The nature of label used, the size of the injection, and the proximity to the injection site may determine whether individual patches or merged patch patterns are most clearly visualized (Rockland et al., 1982; Sesma et al., 1984).

In parallel studies we have been comparing biocytin-labeled intrinsic connectivity patterns in macaque areas V1, V2, and V4. We found patchy connections in all three areas, and we have compared the size and distribution of these biocytin-labeled patches in regions of highest patch density (see Table 1). The diameter of each patch region of terminal label in V4 is roughly $250-450 \mu \mathrm{m}$. This is slightly larger than the patches in V1 and V2, which are roughly 200-300 $\mu \mathrm{m}$ across. We also note that the patch spacing in V4 seems slightly greater than that in $\mathrm{V} 1$ or V2. In V4, average center-to-center spacing is roughly $600 \mu \mathrm{m}$ (range, $450-1300 \mu \mathrm{m}$ ), while in V1 and V2 it is roughly 400-500 $\mu \mathrm{m}$ (although we do observe some clusters of label spaced more widely in V2; see Table 1), which is consistent with earlier measurements using HRP (Rockland and Lund, 

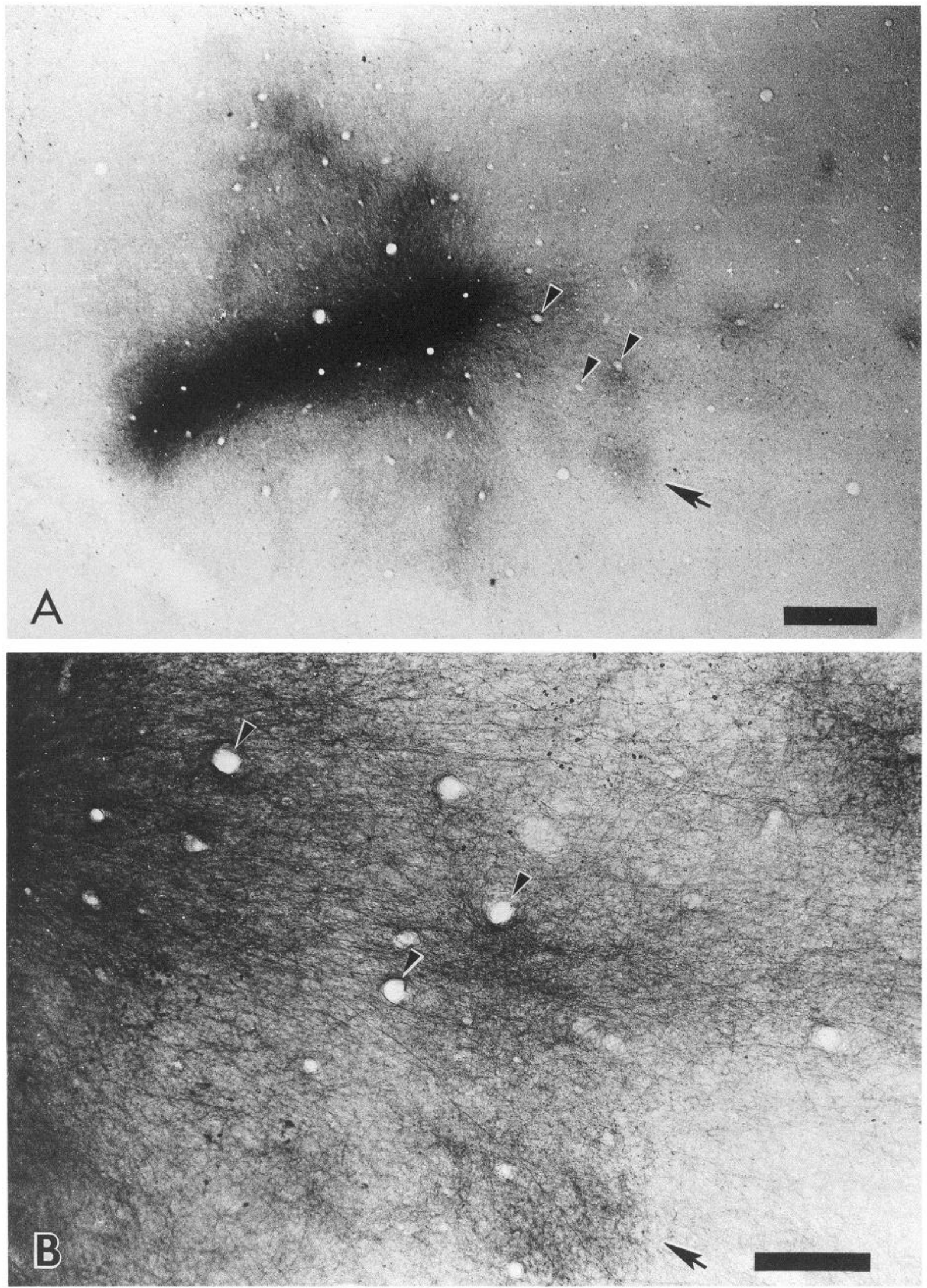

Figure 9. Low- $(A)$ and high-power $(B)$ photomicrographs illustrating adjacent tangential sections of biocytin injection site and patches through layers 1 and 2 following a large pressure injection into layers $1-4$. Fibers terminate in discrete patches as they radiate from the injection site. No cell bodies are seen in layers 1 or $2(B)$. Arrowheads indicate blood vessels seen in both photomicrographs. Arrows indicate the corresponding patch in $A$ and $B$. Scale bars: $A, 500 \mu \mathrm{m} ; B, 200 \mu \mathrm{m}$. 

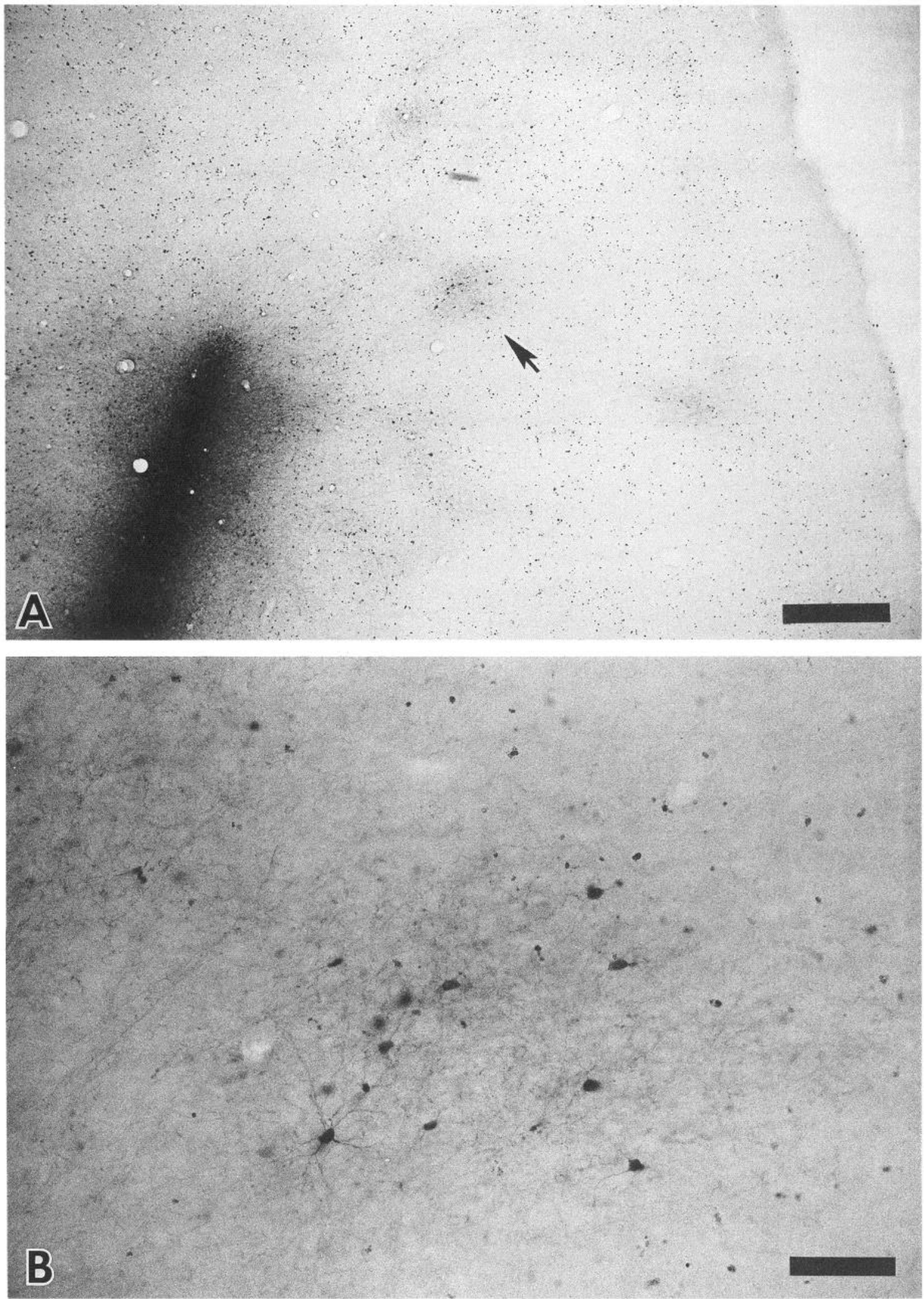

Figure 10. Low- $(A)$ and high-power $(B)$ photomicrographs illustrating a tangential section through layer 3 from the same injection shown in Figure 9. Cell bodies are seen in patches in layer 3. One patch with somata (arrow in $A$ ) is magnified in $B$. The corresponding patch is also seen in Figure 9 (arrow). Scale bars: $A, 500 \mu \mathrm{m} ; B, 50 \mu \mathrm{m}$. 


\begin{tabular}{lllll}
\hline Table 1. & Biocytin patch size and distribution in V1, V2, and V4 \\
& $\begin{array}{l}\text { Patch } \\
\text { diameter } \\
(\mu \mathrm{m})\end{array}$ & $\begin{array}{l}\text { Patches/ } \\
\mathrm{mm}^{2}\end{array}$ & $\begin{array}{l}\text { Area } \\
\text { occupied by } \\
\text { patches }(\%)\end{array}$ & $\begin{array}{l}\text { Patch } \\
\text { interval } \\
(\mu \mathrm{m})\end{array}$ \\
Area & $200-300$ & 5.7 & 27 & $350-500$ \\
V1 & $250-300$ & 5.0 & 30 & $400-1000$ \\
V2 & $250-450$ & 3.8 & 33 & $450-1300$ \\
V4 &
\end{tabular}

Dimensions of patches increase slightly from V1 to V2, and from V2 to V4, though the difference is minimal. About one-quarter to one-third of the cortical tissue in all three areas (measured in regions of highest patch density) is occupied by patches.

1983; Rockland, 1985a). It appears that the reciprocal relationship between patch size and spacing serves to keep the area occupied by patches of labeled terminals in the vicinity of focal injections at a roughly constant one-quarter to one-third in all three areas. The ubiquitous presence of patterned, discontinuous intrinsic connectivity suggests that it may be a fundamental feature of the cortical processing. However, there is considerable debate over the functional significance of these lattices. One possibility is that groups of neurons having similar functional properties are linked. In $\mathrm{V} 1$, there is now good evidence that the patchy connections relate to the topographic organization of orientation preference (Ts'o et al., 1986; T'so and Gilbert, 1988; Gilbert and Wiesel, 1989). In cat primary auditory cortex, the patches seem to interconnect preferentially groups of cells whose characteristic frequencies are roughly the same (Matsubara and Phillips, 1988; Wallace et al., 1991). In V4, little is known about the disposition across the cortex of cells with particular properties, though there are some preliminary indications of modularity within V4. There are reports that groups of cells with similar color preferences may be grouped together (Tootell et al., 1980; Tanaka et al., 1986; Tootell and Born, 1990). Tootell and Born also noted, however, that there do not seem to be orientation columns in V4, but Tanaka et al. have observed grouping of cells that are either unoriented or orientation specific; this issue awaits systematic investigation. If patchy connections do indeed interconnect functionally similar clusters of cells, then the patches we observe in V4 may reflect at least connections between clusters of V 4 cells with similar color properties. This is consistent with the results of Ts'o and Gilbert (1988), who observed correlated firing between V1 cells in different $\mathrm{CO}$ domains when the chromatic properties of the two cells matched.

Another possibility is that the lattice connections relate to the geometry of afferent relays and efferent neurons. In monkey V1, for example, lattice connections in the superficial layers are found to link $\mathrm{CO}$ blob regions (Livingstone and Hubel, 1984a; Burkhalter and Bernardo, 1989). These zones receive distinct afferent fiber terminations and contain clusters of efferent neurons with unique functional characteristics and unique terminal zones in area V2. However, the V1 interblob regions, which do not receive direct geniculate afferents, are also interconnected via intrinsic connections and project to a second compartment in V2. The HRP study by Zeki and Shipp (1989) provides possible evidence for distinct modules in V4 based on the finding of two distinct patterns of V2 efferents to V4, suggesting two topographically separate systems of afferent terminal zones in V4. Van Essen et al. (1990) are also able to define anatomical modules in V4 using fluorescent dyes, based on the distribution of afferents from V2, as well as V4 efferent neurons projecting

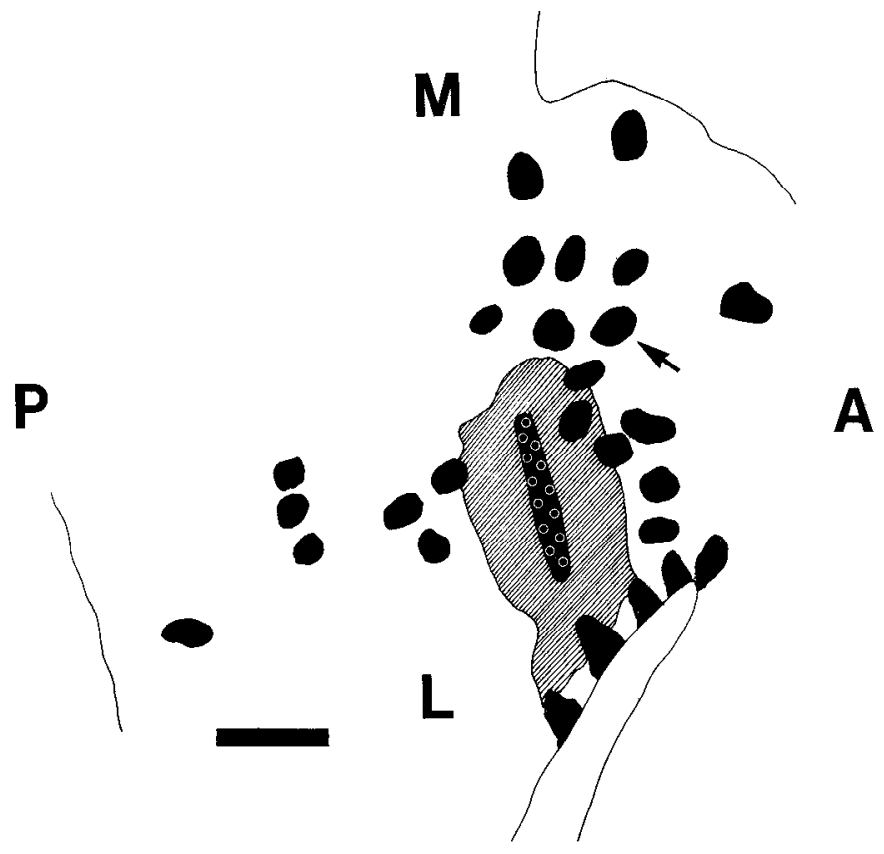

Figure 11. Diagram of reconstructed tangential sections showing patches following a large pressure injection of biocytin as seen in Figures 9 and 10. Arrow indicates the corresponding patch seen in Figures 9 and 10. The region of small white circles shows the core of the injection with the dense radiation of fibers indicated by the hatched area. Note the uneven distribution of patches around the injection site. Eight sections ( $50 \mu \mathrm{m}$ thick, $100 \mu \mathrm{m}$ interval) were used for this reconstruction, and only patches that were present in at least two consecutive sections were drawn. $M$, medial; $L$, lateral; $A$, anterior; $P$, posterior. Scale bar, $1 \mathrm{~mm}$.

to inferotemporal visual cortex. According to these groups' measurements, the V4 modules are roughly $2-4 \mathrm{~mm}$ in diameter. This is far larger than the dimensions of the lattice patch repeat distance we measure in V4. This apparent difference may simply reflect the best resolution obtainable with the larger injections used by these groups, or methodological differences such as the relative sensitivity of HRP or fluorescent dyes versus biocytin. Alternately, we may be observing genuine anatomical substructure within these larger domains, similar to Tootell and Hamilton's (1989) observation of punctate 2-deoxyglucose labeling within the larger CO-rich and -poor stripes in $\mathrm{V} 2$ and also visible in our ongoing studies of lattice connections in V2. The anisotropic distribution of patches we observe around large injection zones might reflect the modular layout of afferents. It is an open question of whether every point in the V4 cortex is part of a continuously repeating offset lattice system, or whether there are points that do not participate in long-distance connections, or participate in a different fashion from that described in this study. The phenomenon of consistently spaced patch label after both large and small injections has been discussed by Mitchison and Crick (1982). On the basis of their theoretical modeling, they suggest that the persistence of a patchy pattern without filling in is a derivation of different connectional constraints for each point on the cortex.

Another potential role for these horizontal connections is to mediate the surround effects seen in V4 neuron responses. Desimone and Schein (1987) and Schein and Desimone (1990) have demonstrated that V4 neurons can be profoundly influenced by stimuli presented outside the cell's classical receptive field. They showed that responses of V4 cells can be inhibited 

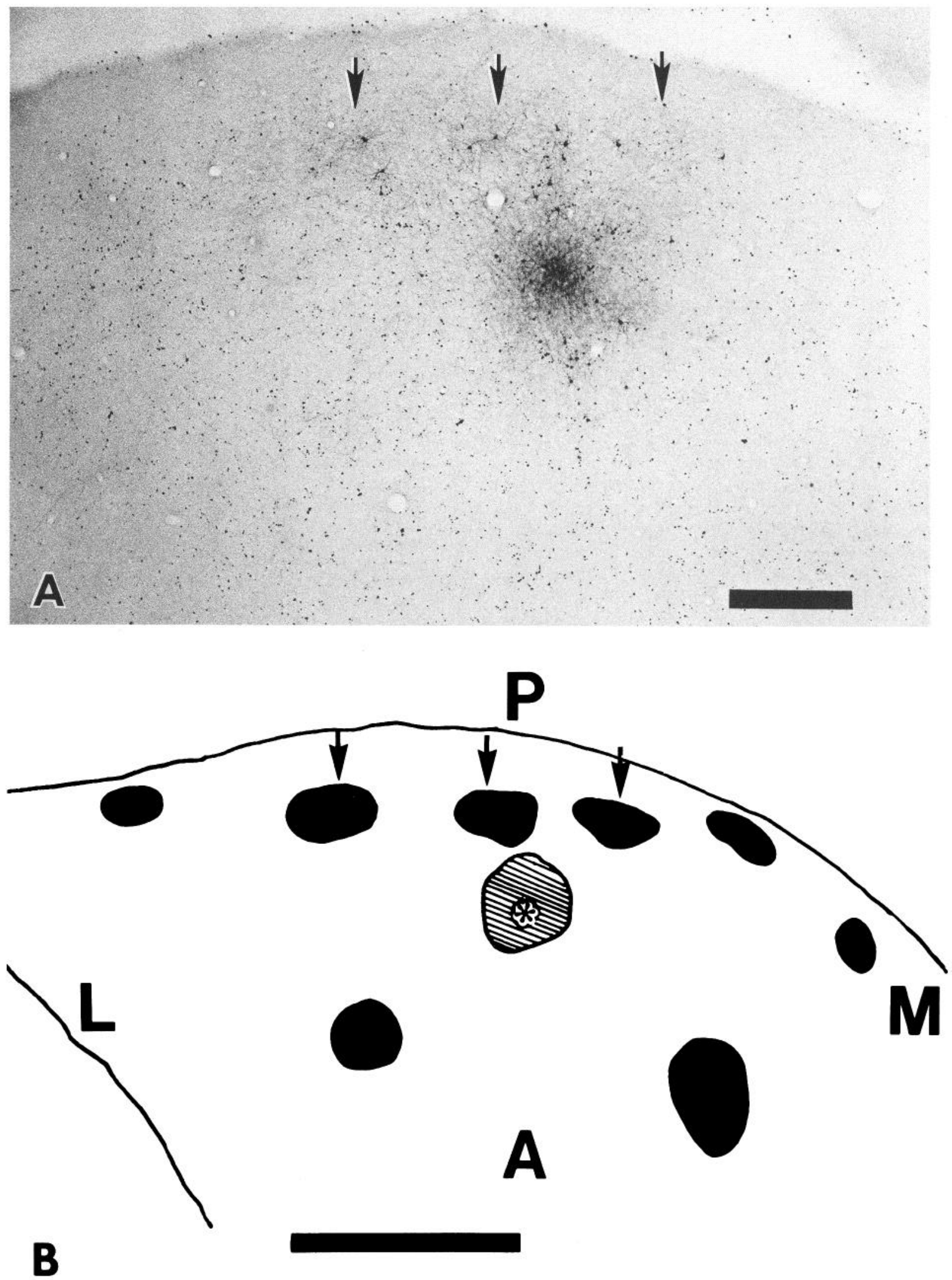

Figure 12. Photomicrograph $(A)$ and serial reconstruction $(B)$ of tangential sections following a small (200 $\mu$ m diameter) iontophoretic injection of biocytin. Note the similar patch size to the large pressure injection of biocytin shown in Figure 11. Arrows in $A$ and $B$ indicate corresponding patches of labeled neurons and terminals. Asterisk indicates the center of the injection. Other conventions are as in Figure 10 . Scale bars: $A$, 500 $\mu \mathrm{m} ; B, 1 \mathrm{~mm}$. 


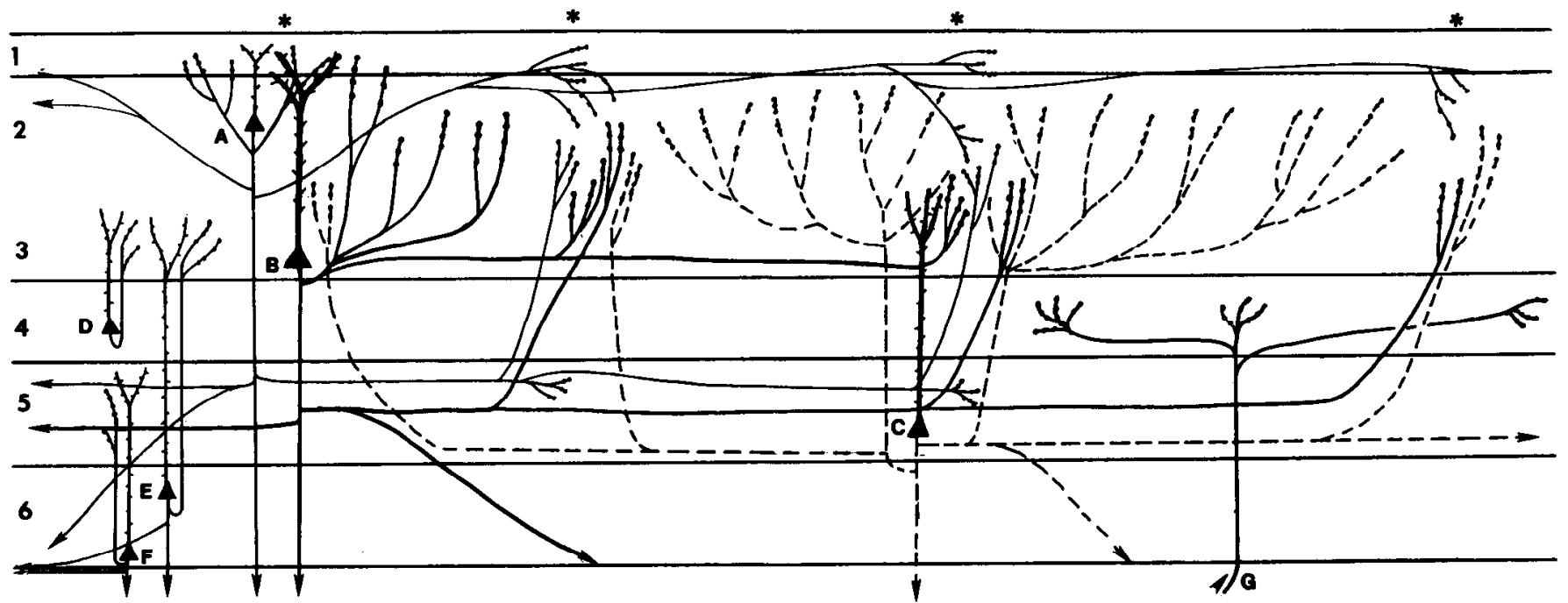

Figure 13. Summary diagram of intrinsic pyramidal neuron projections in area V4 suggested on the basis of patterns of biocytin label seen in serial reconstructions in this study. $A$, Pyramidal neuron of layer 2 has narrowly focused local projections, plus long, distant lateral connections to patches of tissue in layers 1-3 (asterisks) spaced approximately $450-600 \mu \mathrm{m}$ apart around the cell-for up to at least $3 \mathrm{~mm}$ distance (the farthest patches occur medial and lateral to the cell rather than anterior or posterior). The laterally traveling axon trunks lie primarily in layers 1 and 2 , but some also emerge from the descending axon trunk in layer 5, and these may give rise to light patches of terminals in layer 5 , under the patches in the superficial layers, as well as rising collateral branches that travel vertically up to the superficial patches. $B$, Pyramidal neuron of layer 3 gives rise to spreading local connections (up to $1 \mathrm{~mm}$ ) to layers $1-3$, which may preferentially innervate a territory to one side of the radial axis. In addition, long lateral collaterals travel primarily in layer 3 but also in layer 5 to provide terminals to layer $1-3$ patches spaced $450-600 \mu \mathrm{m}$ apart that are also served by axon terminals of layer 2 and 5 pyramids lying at similar positions in the V4 cortical shcet. $C$, Layer 5 pyramidal neuron provides rising axon collaterals (broken lines) to layers 2 and 3 that arborize over a territory reaching up to $1 \mathrm{~mm}$ from the cell of origin. Long, distant axon collaterals of the layer 5 pyramid travel in layer 5, providing rising branches with light terminal arbors spaced at approximately $450-$ $600 \mu \mathrm{m}$ intervals, contributing to patches of connections made by the pyramidal neurons in layers 2 and 3 overlying the neuron in layer 5 . $D$, Pyramidal neuron of layer 4 projects in columnar fashion to layer 3. $E$ and $F$, Pyramidal neurons of layer 6 project in columnar fashion to layers 5 and 3. Afferents from other cortical areas enter layer 4 and give clusters of terminals that, if they travel through the injection, may label well with biocytin (afferents to other layers exist but were not identified in this study).

by stimulation of a region outside the receptive field extending up to $16^{\circ}$ away from the fovea, and this inhibition is critically dependent on both spatial and chromatic properties of the stimulus used in the surround. They found that the suppressive surround of a V4 cell is tuned to the same wavelength as the receptive field itself; that is, maximal suppression occurred when the stimulus wavelength in the surround matched that in the receptive field. They also noted that this suppression seemed to depend on the spatial frequency, orientation, and shape of surround stimulation (Desimone and Schein, 1987). Allman et al. (1985) have observed a similar effect in MT neurons, where moving stimuli in the surround are most effective at suppressing neuronal responses when they move in the same direction as stimuli in the center.

In $\mathrm{V} 4$, we find patchy connections extending over $6-8 \mathrm{~mm}$. According to Gatlass et al. (1988), the cortical magnification factor in V4 is roughly $1 \mathrm{~mm} /$ degree at $4^{\circ}$ eccentricity, and roughly $0.33 \mathrm{~mm} /$ degree at $10^{\circ}$ eccentricity. Although we did not record neuronal activity at each injection site, the placement of our injections is likely to put them all within the central $20^{\circ}$. Therefore, our observed spread of label is sufficient to account for the range over which surround effects are seen. We should note one potential problem with the notion of local connections mediating inhibitory interactions. It has been noted (Rockland ct al., 1982; Rockland and Lund, 1983; LeVay, 1988; McGuire et al., 1991) that the cells providing these clustered lateral connections seem to be all pyramids, that is, of the spine-bearing, excitatory variety. In our material, too, we were not able to identify unequivocally a retrogradely labeled neuron as non- pyramidal unless it was almost within the injection site. Furthermore, pyramidal neurons making local connections have been shown to make synapses predominantly onto dendritic spines; therefore, their main targets are other excitatory neurons (LeVay, 1988; Elhanany and White, 1990; McGuire et al., 1991). This does not, however, rule out inhibition via a multisynaptic pathway, nor does the relative sparseness of lattice connections on non-pyramidal neurons rule out its functional effectiveness, but the point should be noted. Furthermore, there are of course other possible explanations for surround effects, such as feedback from areas to which V4 projects in a forward fashion. Clearly, further physiological studies are needed to define modular organization in V4 better and to resolve the role of these lattice connections.

\section{References}

Adams JC (1977) Technical considerations on the use of horseradish peroxidase as a neuronal marker. Neuroscience $2: 141-145$.

Allman JM, Miezin F, McGuiness E (1985) Stimulus-specific responses from beyond the classical receptive field: neurophysiological mechanisms for local-global comparisons in visual neurons. Annu Rev Neurosci 8:407-430.

Blasdel GG, I und JS, Fitzpatrick D (1985) Intrinsic connections of macaque striate cortex: axonal projections of cells outside lamina $4 \mathrm{C}$. J Neurosci 5:3350-3369.

Burkhalter A (1989) Intrinsic connections of rat primary visual cortex: laminar organization of axonal projections. J Comp Neurol 279:171186.

Burkhalter A, Bernardo KL (1989) Organization of corticocortical connections in human visual cortex. Proc Natl Acad Sci USA 86: 1071-1075. 
Crook JM, Eysel UT, Machemer HF (1991) Influence of GABA-induced remote inactivation on the orientation tuning of cells in area 18 of feline visual cortex: a comparison with area 17 . Neuroscience 40:1-12.

Cusick CG, Kaas JH (1988) Cortical connections of area 18 and dorsolateral visual cortex in squirrel monkeys. Vis Neurosci 1:211-237.

Desimone R, Schein SJ (1987) Visual properties of neurons in area V4 of the macaque: sensitivity to stimulus form. J Neurophysiol 57: $835-868$.

Desimone R, Fleming J, Gross CG (1980) Prestriate afferents to inferior temporal cortex: an HRP study. Brain Res 184:41-55.

Desimone R, Schein SJ, Moran J, Ungerleider LG (1985) Contour, color and shape analysis beyond the striate cortex. Vision Res 25: $441-452$.

DeYoe EA, Hockfield S, Garren H, Van Essen DC (1990) Antibody labeling of functional subdivisions in visual cortex: Cat-301 immunoreactivity in striate and extrastriate cortex of the macaque monkey. Vis Neurosci 5:67-81.

Elhanany E, White EL (1990) Intrinsic circuitry: synapses involving the local axon collaterals of corticocortical projection neurons in the mouse primary somatosensory cortex. J Comp Neurol 291:43-54.

Fenstemaker SB, Olson CR, Gross CG (1984) Afferent connections of macaque visual areas V4 and TEO. Invest Opthalmol Vis Sci [Suppl] 25:213.

Fitzpatrick D, Lund JS, Blasdel GG (1985) Intrinsic connections of macaque striate cortex: afferent and efferent connections of lamina 4C. J Neurosci 5:3329-3349.

Gattass R, Sousa APB, Gross CG (1988) Visuotopic organization and extent of V3 and V4 of the macaquc. J Neurosci 8:1831-1845.

Gilbert CD, Wiesel TN (1983) Clustered intrinsic connections in cat visual cortex. J Neurosci 3:1116-1133.

Gilbert CD, Wiesel TN (1989) Columnar specificity of intrinsic horizontal and corticocortical connections in cat visual cortex. J Neurosci 9:2432-2442.

Hockfield S, McKay RDG, Hendry SHC, Jones EG (1983) A surface antigen that identifies ocular dominance columns in the visual cortex and laminar features of the lateral geniculate nucleus. Cold Spring Harbor Symp Quant Biol 48:877-889.

Horikawa K, Armstrong WE (1988) A versatile means of intracellular labeling: injection of biocytin and its detection with avidin conjugates. J Neurosci Methods 25:1-11.

King MA, Lewis PM, Hunter BE, Walker OW (1989) Biocytin: a versatile anterograde neuroanatomical tract-tracing alternative. Brain Res 497:361-367.

Kisvarday ZF, Eysel UT (1990) Relationship between excitatory and inhibitory long range connections in the cat visual cortex. Soc Neurosci Abstr 16:1271.

Lachica EA, Mavity-Hudson EA, Casagrande VA (1991) Morphological details of primate axons and dendrites revealed by extracellular injection of biocytin: an economic and reliable alternative to PHAL. Brain Res 564:1-11.

LeVay S (1988) Patchy intrinsic projections in visual cortex, area 18, of the cat: morphological and immunocytochemical evidence for an excitatory function. J Comp Neurol 269:265-274.

Levitt JB, Yoshioka T, Lund JS (1991) Patchy intrinsic connections in macaque area V4. Soc Neurosci Abstr 17:117.

Livingstone MS, Hubel DH (1984a) Anatomy and physiology of a color system in the primate visual cortex. J Neurosci 4:309-356.

Livingstone MS, Hubel DH (1984b) Specificity of intrinsic connections in primate primary visual cortex. $J$ Neurosci $4: 2830-2835$.

Maguire WM, Baizer JS (1984) Visuotopic organization of the prelunate gyrus in rhesus monkey. J Neurosci 4:1690-1704.

Matsubara JA, Phillips DP (1988) Intracortical connections and their physiological correlates in the primary auditory cortex (AI) of the cat. J Comp Neurol 268:38-48.

Matsubara JA, Cynader MS, Swindale NV (1987) Anatomical properties and physiological correlates of the intrinsic connections in cat area 18. J Neurosci 7:1428-1446.

McGuire BA, Gilbert CD, Rivlin PK, Wiesel TN (1991) Targets of horizontal connections in macaque primary visual cortex. J Comp Neurol 305:370-392.

Mitchison G, Crick F (1982) Long axons within the striate cortex: their distribution, orientation and patterns of connection. Proc Nat Acad Sci USA 79:3661-3665.

Rockland KS (1985a) A reticular pattern of intrinsic connections in primate area V2 (area 18). J Comp Neurol 235:467-478.

Rockland KS (1985b) Anatomical organization of primary visual cortex (area 17) in the ferret. J Comp Neurol 241:225-236.

Rockland KS, Lund JS (1983) Intrinsic laminar lattice connections in primate visual cortex. J Comp Neurol 216:303-318.

Rockland KS, Lund JS, Humphrey AL (1982) Anatomical banding of intrinsic connections in striate cortex of tree shrews. J Comp Neurol 209:41-58.

Schein SJ, Desimone R (1990) Spectral properties of V4 neurons in the macaque. J Neurosci 10:3369-3389.

Schein SJ, Marrocco RT, DeMonasterio FM (1982) Is there a high concentration of color-selective cells in area V4 of monkey visual cortex? J Neurophysiol 47:193-213.

Sesma MA, Casagrande VA, Kaas JH (1984) Cortical connections of area 17 in tree shrews. J Comp Neurol 230:337-351.

Tanaka M, Weber H, Creutzfeldt OD (1986) Visual properties and spatial distribution of neurones in the visual association area on the prelunate gyrus of the awake monkey. Exp Brain Res 65:11-37.

Tootell RB, Silverman MS, DeValois RL (1980) Color-dependent deoxyglucose patterns within macaque cortex. Invest Opthalmol Vis Sci [Suppl] 21:226.

Tootell RBH, Born RT (1990) Columns beyond V1 and V2 in macaque visual cortex: a double-label deoxyglucose study. Soc Neurosci Abstr 16:292.

Tootell RBH, Hamilton SL (1989) Functional anatomy of the second visual area (V2) in the macaque. J Neurosci 9:2620-2644.

T'so DY, Gilbert CD (1988) The organization of chromatic and spatial interactions in the primate striate cortex. J Neurosci 8:1712-1727.

T'so DY, Gilbert CD, Wiesel TN (1986) Relationships between horizontal connections and functional architecture in cat striate cortex as revealed by cross-correlation analysis. J Neurosci 6:1160-1170.

Ungerleider LG, Mishkin M (1982) Two cortical visual systems. In: Analysis of visual behavior (Ingle DJ, Goodale MA, Mansfield RW, eds), pp 549-586. Cambridge, MA: MIT Press.

Van Essen DC, Zeki SM (1978) The topographic organization of rhesus monkey prestriate cortex. J Physiol (Lond) 277:193-226.

Van Essen DC, Felleman DJ, DeYoe EA, Olavarria J, Knierim J (1990) Modular and hierarchical organization of extrastriate visual cortex in the macaque monkey. Cold Spring Harbor Symp Quant Biol 55:679696.

Wallace MN, Kitzes LM, Jones EG (1991) Intrinsic inter- and intralaminar connections and their relationship to the tonotopic map in cat primary auditory cortex. Exp Brain Res 86:527-544.

Zeki SM (1971) Cortical projections from two prestriate areas in the monkey. Brain Res 34:19-35.

Zeki SM (1973) Colour coding in rhesus monkey prestriate cortex. Brain Res 53:422-427.

Zeki SM (1980) The representation of colors in the cerebral cortex. Nature 284:412-418.

Zeki SM, Shipp S (1989) Modular connections between areas V2 and V4 of macaque monkey visual cortex. Eur J Neurosci 1:494-506. 